\title{
Positive and Negative Social Support and HPA-axis Hyperactivity: Evidence from Glucocorticoids in Human Hair
}

\section{Eleonora Iob ${ }^{1}$, Clemens Kirschbaum ${ }^{2}$, Andrew Steptoe ${ }^{1}$}

${ }^{1}$ Department of Behavioural Science and Health, University College London, 1-19 Torrington Place, London, WC1E 6BT.

${ }^{2}$ Department of Psychology, Technische Universität Dresden, Germany.

Correspondence to:

Eleonora Iob, Soc-B CDT (ESRC \& BBSRC)

Department of Behavioural Science and Health, Institute of Epidemiology and Health Care University College London

Visiting address: 1-19 Torrington Place, London WC1E 7HB

Postal address: UCL, Gower Street, London WC1E 6BT

eleonora.iob.17@ucl.ac.uk 


\begin{abstract}
Introduction. While positive social support is associated with lower prevalence of disease and better treatment outcomes, negative social relationships can instead have unfavourable consequences for several physical and mental health conditions. However, the specific mechanisms by which this nexus might operate remain poorly understood. Hypothalamicpituitary-adrenal (HPA) axis hyperactivity owing to psychosocial stress has been proposed as a potential pathway underlying the link between social support and health. Hair glucocorticoids such as cortisol and cortisone are emerging as promising biomarkers of longterm retrospective HPA activation. Therefore, the aim of this investigation was to examine the effects of positive and negative experiences of social support within key relationships (i.e. spouse/partner, children, other family members, and friends) on cortisol and cortisone.
\end{abstract}

Methods. These associations were tested in a sample of 2,520 older adults (mean age 68.1) from the English Longitudinal Study of Ageing. Hair samples were collected in wave 6 (2012/13). To understand the impact of cumulative exposure to poor social support, the analysis used self-reported data from waves 4 (2008/09) and 6. Covariates included demographic, socioeconomic, lifestyle, and hair characteristics.

Results. In cross sectional analyses, lower positive support from all sources and specifically from children were associated with higher cortisol. Additionally, lower positive support from children was positively associated with cortisone. Similarly, higher overall negative support was related to higher cortisol, and greater negative support from children was also positively associated with cortisone. In longitudinal analyses, there was evidence for positive associations between hair glucocorticoids and cumulative exposure to poorer social support. Conclusions. Experiences of low positive and high negative social support, particularly from children, were both related to higher hair glucocorticoids. Hence, social relationships of 
poorer quality in later life may have adverse effects on the HPA axis thereby increasing the individual's susceptibility to poor health.

Key words: cortisol; cortisone; social support; HPA axis; stress. 


\section{Introduction}

Social support can be defined as the social resources perceived by individuals to be available to them as well as those that are actually provided in the context of helping relationships (Gottlieb and Bergen, 2010). There is convincing evidence that social support is a crucial factor in the maintenance of health and an essential component of human wellbeing (Cohen et al., 2000; Uchino, 2006). Several prospective studies have demonstrated how both functional and structural aspects of social support can affect morbidity and mortality from a wide range of diseases (Holt-Lunstad et al., 2010). A better understanding of this relationship between social support and health is particularly important in contemporary industrialised societies. Indeed, despite huge advances in contemporary communication technology in an epoch of mass-globalisation, both the quality and quantity of subjective social connections appear to be decreasing (McPherson et al., 2006; Office for National Statistics, 2016).

Social interactions are not inherently positive in nature, and instead entail both rewards and costs (Rook, 1997). For instance, having a larger social network could lead to higher interpersonal conflict in the context of unhealthy social exchanges (Cohen et al., 2000). Therefore, over the last two decades, researchers have devoted increasingly more attention to the negative (e.g. criticism and demands), as well as positive (e.g. affection and understanding) aspects of social support. The dual focus on positive and negative social support rests on the finding that they are two relatively distinct constructs (Fiori and Consedine, 2013). In this vein recent evidence indicates that, whilst positive social support can promote health and wellbeing, negative social interactions can predispose the individual to poorer health outcomes (Newsom et al., 2005; Croezen, 2012; Khondoker et al., 2017). Nevertheless, it remains unclear which dimension or source of social support has the greatest impact on health. 
Notwithstanding these limitations, the nexus between social support and health is now well established in the research literature. However, the specific pathways by which this might operate remain poorly understood (Holt-Lunstad et al., 2010). There are two broad sets of mechanisms through which psychosocial factors may influence health - namely, the behavioural and the psychobiological (Steptoe et al., 2005). With respect to behavioural factors, there is some evidence that negative social support is associated with current smoking, physical inactivity, overweight, and excessive alcohol consumption (Croezen et al., 2012). However, the association between social support and health appears to be partly independent of behavioural risk factors (Berkman and Krishna, 2015), and there also are instances of supportive relationships which ultimately promote damaging health behaviours (Uchino, 2006).

An alternative pathway is represented by psychobiological processes, where hypothalamic-pituitary-adrenal (HPA) axis hyperactivity owing to psychosocial stress might be a key mediator (DeVries, et al., 2003; Hostinar and Gunnar, 2013). According to the stress-buffering hypothesis, social support can either provide a buffer against stress, serving as a coping resource against the negative effects of adverse life events, or be itself a source of stress (Cohen et al., 2000). Activation of the HPA axis is one of the most thoroughly characterised neuroendocrine response to stress (McEwen, 1998). Consequently, the glucocorticoid hormone cortisol, a primary product of the HPA axis, has been proposed as a key biomarker underlying the relationship between health and psychosocial factors.

Cortisol is produced in the adrenal glands via the enzyme 11-beta-hydroxysteriod dehydrogenase (11B-HSD) type 1. Higher levels of this hormone are implicated in the aetiology of numerous cardiometabolic, inflammatory, endocrine, and neural disorders (Girod and Brotman, 2004; McEwen, 2007; Hackett et al., 2016; Jackson et al., 2017), as well as mental health problems (Adam et al., 2017). Cortisone is another glucocorticoid hormone 
which is metabolised from cortisol in the peripheral tissue by the enzyme 11B-HSD type 2, and is typically considered as an inactive metabolite because it has much lower glucocorticoid activity than cortisol (Raul et al., 2004). In addition, the ratio of cortisol to cortisone can be used as an indirect measurement of 11B-HSD enzymatic activity, which is responsible for regulating overall glucocorticoid action (Weber et al., 2000). Similarly to cortisol, elevated levels of cortisone and cortisol/cortisone ratio have been found to be associated with different mental and physical health factors, including depression, selfreported stress, body mass index, obesity, and hypertension (Quinkler and Stewart, 2003; Romer et al., 2009; Vanaelst et al., 2013; Rippe et al., 2016; Scharlau et al., 2018). Moreover, the importance of assessing cortisone and the ratio in stress-related research has been reinforced by evidence showing altered 11B-HSD activity under stress conditions (Quinete et al., 2015).

A number of studies have found evidence for positive associations between cortisol and measures of social isolation, loneliness, and perceived social support (Steptoe et al., 2004; Adam et al., 2006; Stafford et al., 2013; Staufenbiel et al., 2014). However, no research has yet addressed the effects of both positive and negative social relationships on cortisol, cortisone, and their ratio. Moreover, until recently glucocorticoid hormones have been predominantly measured in saliva, serum, or urine, which can only represent the dynamics of glucocorticoid output over short periods up to 24 hours (Staufenbiel et al., 2015). In contrast, measurements in hair provide quantification of glucocorticoid output over several weeks, and are not influenced by the acute variations related to momentary events and moods. As a result, hair concentrations of cortisol and cortisone are emerging as promising biomarkers of long-term HPA activation (Stalder and Kirschbaum, 2012; Stalder et al., 2017).

Therefore, the aim of this study was to determine the relative influence of positive and negative experiences of social support on hair cortisol, cortisone, and their ratio $\left(\mathrm{R}_{\mathrm{hcc}}\right)$ in a 
sample of older men and women. Since different relationships may perform different functions in the social networks of older people (Khondoker et al., 2017), the associations between positive and negative support and hair glucocorticoids were analysed separately according to source type (i.e. partner/spouse, children, other immediate family members, and friends). Furthermore, in order to understand the impact of cumulative exposure to poor social support, the analysis used data on the participants' quality of social relationships evaluated in retrospect over four years. We hypothesised that: 1) positive social support would be related to lower cortisol, cortisone, and $\mathrm{R}_{\mathrm{hcc}}$, whereas negative social support would be associated with higher levels of hair glucocorticoids; 2) these associations would be larger for emotionally-closer relationships such as partner/spouse and children; and 3) cumulative exposure to low positive/high negative social support over a four-year period would be associated with higher glucocorticoids.

\section{Methods}

\subsection{Study sample}

The data came from the English Longitudinal Study of Ageing (ELSA), a prospective study of women and men aged 50 years and over living in England. The study began in 2002 with an original sample of 12,099 participants, who were drawn from the Health Survey for England. The methods of data collection and sample design are detailed at www.elsaproject.ac.uk. Comparisons of the sample's sociodemographic features with the national census suggest that it is representative of the general English population (Steptoe et al., 2013). During the assessment by study nurses in wave 6 (2012/13), hair samples were collected to measure cortisol and cortisone. Out of the 7,699 participants who participated in the nurse interview, hair samples were collected from 5,451 individuals. However, owing to financial constraints, hormone levels were assayed only from 2,685 participants, prioritising 
those who had participated in the maximum number of previous waves of data collection (Steptoe et al., 2017). There were 84 individuals who were excluded from the study because they had hormone levels too low to be detected or too extreme, resulting in a sample of 2,601 participants. In addition, to examine the effect of cumulative exposure to poor social support, the analysis used data from the self-completion questionnaire in waves $4(2008 / 09)$ and 6 . In the sample with detectable hair glucocorticoids, there were 80 individuals who did not return the self-completed interview in wave 4 . Thus, the final analytical sample included 2,520 respondents. All respondents provided informed consent. Ethical approval was obtained from the National Research Ethics Service.

\subsection{Measurements}

\subsubsection{Hair Cortisol and Cortisone}

During the nurse visit, hair strands of approximately $3 \mathrm{~cm}$ were collected from the posterior vertex as close to the scalp as possible. Participants were excluded from the hair sample in the following circumstances: pregnancy, breastfeeding, certain scalp conditions, having less than two $\mathrm{cm}$ of hair length, and inability to sit with head remaining still. A more detailed description of the hair sampling process can be found at http://www.elsaproject.ac.uk/uploads/elsa/docs_w6/project_instructions_nurse.pdf. The hair analysis was conducted by the Technische Universität Dresden in Germany. As described in Gao et al. (2016), following a standard wash and steroid extraction procedure, glucocorticoid levels were quantified by high performance liquid chromatography-mass spectrometry (LC/MS). Cortisol and cortisone concentrations were expressed in pg/mg. Based on an average hair growth of approximately $1 \mathrm{~cm}$ per month (Kirschbaum et al., 2009), the $3 \mathrm{~cm}$ hair segment closest to the scalp represents average glucocorticoid concentrations accumulated over three months prior to sampling. Hair specific characteristics that could affect hormonal levels (e.g. 
dyeing or chemical treatments) were assessed by self-reports. The $\mathrm{R}_{\mathrm{hcc}}$ was calculated by dividing hair cortisol levels by cortisone concentrations.

\subsubsection{Positive and negative social support}

Positive and negative experiences of social support were measured based on items administered in a self-completion questionnaire. A set of three items were used to measure positive support, while four items were used to represent negative social exchanges

(Appendix A). The same sets of items were used to measure the quality of each of four types of close relationship separately (Spouse/partner, children...). Responses were measured on a 4-point scale ranging from 1 ('not at') to 4 ('a lot'). For each relationship, positive and negative scores were then averaged and categorised into 'low' (1-2), 'medium' (3), 'high' (4), or 'no source' (positive support), and 'low' (1), 'medium' (2), 'high' (3-4), or 'no source' (negative support). This approach minimised the amount of missing data because some relationships were not available for all participants, and allowed us to examine the effect of not having a specific source of support compared with having a poor relationship. In addition, we calculated overall scores for low positive and high negative support across all four sources, where respondents were assigned a score of one if they reported low positive/high negative support for each relationship. Furthermore, a combined measure of positive and negative support was calculated by summing together the overall low positive and high negative scores. Cross-sectional analyses were based on responses in wave 6 , while in longitudinal analyses, the effect of cumulative exposure to low positive/high negative social support was evaluated based on responses from waves 4 (2008/09) and 6. For each source and dimension of social support, a categorical variable was created for whether the participant had been exposed to low positive/high negative social support two, one, or no 
times across the two time points. Overall scores were also computed by summing together the overall positive, negative, and combined scores from waves 4 and 6.

\subsubsection{Sociodemographic variables, lifestyle factors, and hair characteristics}

The analyses were adjusted for sociodemographic, lifestyle, and hair characteristics. Sex was a dichotomous variable, while age was measured on a continuous scale. Wealth and educational attainment were used as indicators of socioeconomic position. Wealth was derived from a comprehensive assessment of the respondent's economic resources, excluding pension wealth, and was categorised into quintiles across all ELSA respondents who participated in wave 6. Educational attainment was a categorical variable coded as 'graduate', 'primary/secondary school', or 'no qualifications'. Body Mass Index (BMI) was derived from measures of height and body weight collected during the nurse assessment in wave 6 . Current smoking status was represented by a dichotomous variable (yes/no). Physical activity was measured using data about mild intensity (e.g. laundry, home repairs), moderate intensity (e.g. walking, cleaning the car), and vigorous activity (e.g. cycling, aerobics). Participants indicated the frequency of participation based on a four-point scale ranging from 'hardly ever or never' to 'more than once a week'. In the current analysis, people were classified as sedentary if they reported no light, moderate or vigorous intensity activity hardly ever. Lastly, we also controlled for a number hair characteristics which may influence hormonal concentrations. These were: hair colour (brunette, red/ginger, blonde, white/grey, mix grey/other colour) and chemical treatments (yes/no).

\subsection{Statistical Analyses}

RStudio version 1.0.136 for Windows was used in all statistical analyses. Cortisol and cortisone were positively skewed, and therefore logarithmic transformation was applied to 
achieve normal distribution. The associations between glucocorticoid concentrations and social support were tested using multiple linear regression analysis. Each outcome variable (i.e. cortisol, cortisone, $\mathrm{R}_{\mathrm{hcc}}$ ) was modelled in separate regression models. In a first step, partially-adjusted models were performed examining the effects of each social support variable on hair glucocorticoid levels separately, with adjustment for sex and age (Model 1). In the next step, fully-adjusted regression models were run including all covariates used in the analysis (Model 2). Lastly, the independent effects of each social relationship were tested entering all source-specific social support variables simultaneously, but separately for positive and negative experiences due to potential multicollinearity issues (Model 3). Missing data were accounted for by multiple imputation by chained equations using the R's package 'Mice' (Van Buuren and Groothuis-Oudshoorn, 2011). Missing information was imputed on all variables for those respondents with available glucocorticoid values. All analysis variables were used as predictors in the imputation models. Missing data is estimated under the Missing at Random Assumption (MAR) (Little and Rubin, 2002). In the present analysis, MAR implies that if all the variables that are associated with the missing data generating mechanism are used in the imputation models, then estimates can be reliably computed for all participants with missing data (Ploubidis et al., 2014). Therefore, since socioeconomic position and age are the main drivers of attrition in ELSA (Steptoe et al., 2013) and were used as predictors in the imputation models, this assumption is likely to be met. Twenty imputed datasets were created and the pooled estimates from the regression models are reported. A comparison of observed and imputed data demonstrated that these values were very similar (Appendix B), thus suggesting that the imputation process was conducted appropriately. 


\section{Results}

\subsection{Sample characteristics}

The characteristics of the study sample are summarised in Table 1. Participants were on average 68.1 years old, and $58.7 \%$ were women. The majority had primary or secondary school qualifications, and there was a higher proportion of participants in the highest wealth quintile. The sample was on average overweight, only $10.1 \%$ were current smokers, and most of them did not have a sedentary lifestyle. Cortisone concentrations were considerably higher than cortisol, and they showed a significant positive correlation with each other $(r=$ $0.279, p<.001)$. Descriptive statistics of the negative and positive social support measures are shown in Table 2. For all relationships, the majority of participants reported high positive/low negative social support in wave 6 , and only a small proportion of them had experienced low positive/high negative social support twice across waves 4 and 6 . There was a moderate positive correlation between overall low positive and high negative social support scores $(r=0.137, p<.001)$. Chi-square tests of independence indicated that positive and negative support variables within each relationship were significantly correlated to each other. Furthermore, significant associations were also found between positive/negative support variables across different relationships (e.g. positive support from partner and children).

\subsection{Associations with hair cortisol}

The regressions of hair cortisol on positive and negative experiences on social support are reported in Table 3. In cross-sectional analyses, the overall score for low positive support was significantly associated with cortisol, an effect which was sustained also after adjustment for the other covariates as indicated in Model $2(\beta=0.048, p=0.018)$. This suggests that for every one point increase in the low positive support score the expected log transformed 
cortisol value increased by 0.05 standard deviation units on average. Similarly, the overall score for high negative support was positively associated with cortisol concentrations both in partially and fully adjusted models (Model 2: $\beta=0.039, p=0.051$ ). In addition, the combined positive + negative score was also associated with higher cortisol levels independently of all covariates (Model 2: $\beta=0.058, p=0.004$ ), and its effect size was larger than those observed for the two scores separately. When social support was tested separately for each social relationship, evidence was found for a significant association between social support from children and hair cortisol, which was robust to full adjustment for all covariates and independent from the other sources of positive support. Specifically, participants who reported high and medium positive support from children had on average a log transformed cortisol value of $0.081(p=0.050)$ and $0.084(p=0.023)$ standard deviations lower than those with low children support respectively (Model 3).

Cortisol was also associated with cumulative exposure to poor social support over a four-year period. Higher scores on overall low positive $(\beta=0.055, p=0.006)$ and positive + negative $(\beta=0.062, p=0.002)$ scores across waves 4 and 6 were both positively associated with cortisol independently of all covariates (Model 2). Importantly, the magnitude of their effects was somewhat larger than in cross-sectional analyses. Overall negative support was found to be positively associated with cortisol. However, this effect no longer reached statistical significance in fully adjusted analysis (Model 2: $\beta=0.038, p=0.060$ ). Sourcespecific analyses (see Supplementary tables online; Appendix C) demonstrated that participants who had been exposed to low positive support from children twice had an average cortisol value of 0.038 standard deviations higher than those who reported high or medium positive support from children at both time points independently from all covariates $(p=0.050)$. 


\section{3. $\quad$ Associations with hair cortisone}

The regressions of cortisone on positive and negative experiences of social support are shown in Table 4. In cross-sectional analyses, the overall scores for positive and negative support, as well as their combination, were not significantly associated with cortisone. However, source-specific effects of positive and negative support from children demonstrated significant associations with cortisone levels. Participants who reported high or medium positive support from children had an average log transformed cortisone value of $0.010(p=$ $0.012)$ and $0.083(p=0.016)$ standard deviation units lower than those with low positive support respectively, independently of the other covariates and sources of social support (Model 3). Furthermore, low and medium negative support from children, as well as having no children, were all significantly associated with a decrease in cortisone of 0.177 ( $p=$ $0.002), 0.127(p=0.008)$, and $0.092(p=0.027)$ standard deviations respectively, compared to the group of respondents with high negative support (Model 3).

Similarly, longitudinal analyses provided no evidence for significant associations between cortisone and cumulative exposure to overall positive and negative support. Nevertheless, there was a significant effect of children support in source-specific analyses (Appendix C). In particular, participants reporting low positive children support at both or one time point had on average a log transformed cortisone score of $0.041(p=0.049)$ and $0.038(p=0.046)$ standard deviations higher than their counterparts independently of all covariates.

\subsection{Associations with the $R_{h c c}$}

In cross-sectional analyses, the $\mathrm{R}_{\mathrm{hcc}}$ showed significant associations with the overall support scores after adjustment for all covariates (Table 5; Model 2). For every one point increase in the low positive, high negative, and positive + negative scores, the mean $R_{\text {hcc }}$ was 
expected to increase on average by $0.039(p=0.048), 0.053,(p=0.008)$, and $0.059(p=$ 0.003) standard deviations respectively. Similar associations were also found in longitudinal analyses. In fact, cumulative exposure to overall low positive $(\beta=0.048, p=0.015)$ and high negative $(\beta=0.055, p=0.08)$ social support, as well as their combination $(\beta=0.066, p=$ 0.001), were all positively related to the $\mathrm{R}_{\mathrm{hcc}}$ independently of the other study covariates, and with larger effect sizes than those observed in cross-sectional analyses (Model 2). However, the favourable effect of higher quality support from children on cortisol and cortisone was not observed for their ratio (Appendix C).

\subsection{Effects of sociodemographic, lifestyle, and hair characteristics}

Lastly, we found evidence for significant associations between hair glucocorticoid hormones and a number of demographic, socioeconomic, lifestyle, and hair characteristics which were used as covariates in the main analysis (Appendix D). In fully adjusted models, higher BMI and lower wealth were associated with higher cortisol and cortisone. Elevated cortisone concentrations were also observed for males, smokers, and participants with darker or not chemically treated hair. In addition, the $\mathrm{R}_{\mathrm{hcc}}$ was positively associated with female sex, age, and lighter or chemically treated hair.

\subsection{Sensitivity analyses}

In order to assess potential bias due to missing data, all models were rerun applying list-wise deletion on all variables. This resulted in a sample of 1,524 participants. The pattern of associations between positive and negative social support and glucocorticoid levels remained almost unchanged. There were some variations in the significance level of the source-specific social support measures. However, this is likely to be due to the reduced sample size, and therefore power of the analysis to detect significant differences between 
subgroups. Supplementary tables for these analyses can be found in the online version of the article (Appendix E).

\section{Discussion}

\subsection{Summary of main findings}

This study investigated the associations of hair cortisol, cortisone, and their ratio with both positive and negative experiences of social support within key relationships (i.e. partner/spouse, children, other family members, and friends) in a sample of older adults from ELSA. The first hypothesis proposed that positive support would have a favourable effect on hair glucocorticoids, whilst negative social relationships would lead to higher hormone levels. The results confirmed that participants who reported lower positive or greater negative social support across all sources had higher levels of cortisol, as well as an elevated $\mathrm{R}_{\mathrm{hcc}}$. In addition, lower overall positive support was associated with higher negative support, and their combination led to an even higher level of glucocorticoid concentrations as compared with their individual effects. According to the second hypothesis, the association between social support and hair glucocorticoids would be larger for emotionally-closer relationships such as partner/spouse and children. The results supported this prediction in relation to children support, since this was the source-specific measure exhibiting the largest effects on both hormones. Lastly, the third hypothesis proposed an adverse effect of cumulative exposure to poor social support on hormone levels. In line with this prediction, overall low positive and high negative social support evaluated in retrospect over a four-year period were associated with an increase in both cortisol and the $\mathrm{R}_{\mathrm{hcc}}$. Furthermore, greater hormone concentrations were observed in participants reporting low positive support from children at both measurement points, a finding which further corroborates the second study prediction. These 
associations were also independent of relevant demographic, socioeconomic, lifestyle, and hair characteristics.

\section{2. $\quad$ Interpretation of the results in relation to previous work}

To our knowledge, this is the first study to investigate the influence of positive and negative social support on hair cortisol, cortisone, and their ratio. Although associations between cortisol and other aspects of social relationships such as isolation and loneliness have been documented in previous studies (e.g. Steptoe et al., 2004; Adam et al., 2006; Stafford et al., 2013), no research has yet investigated the positive, as well as negative, qualitative dimensions of social support in relation to the HPA axis. Moreover, the majority of studies have assessed cortisol using salivary or blood measurements which can fluctuate considerably over the day and in response to different activities or moods. Scalp hair cortisol instead allows to measure long-term HPA activity (Stalder and Kirschbaum, 2012). It may therefore be well suited to the analysis of the psychobiological pathways linking social support and health which may take time to unfold. Consequently, this study makes a fundamental contribution to the current state of knowledge. Specifically, it demonstrated that, while higher positive support within close relationships was associated with lower concentrations of hair cortisol, conversely, higher negative social support led to an increase in hormone levels. In addition, it showed that chronically elevated cortisol concentrations were associated with cumulative measures of poor social support, thus providing a more comprehensive characterisation of the interplay between social relationships and HPA function over time. HPA axis hyperactivity is one of the best characterised neuroendocrine response to stress (DeVries et al., 2003), which also plays a critical role for physical and mental health (Girod and Brotman, 2004; Hackett et al., 2016; Adam et al, 2017). Thus, this provides further support for the stress-buffering hypothesis of social support (Cohen et al., 
2000), as well as convincing evidence for the possible presence of a specific psychobiological pathway underlying the nexus between social support and health. The relationships between hair glucocorticoids and social support were also independent of a number of behavioural and lifestyle factors (i.e. adiposity, smoking, and physical inactivity) which are associated with both cortisol (Stalder et al., 2017; Steptoe et al., 2017) and social support (Croezen et al., 2012). This therefore indicates that the psychobiological and behavioural pathways through which social relationships may influence health are partly independent from each other.

Another original aspect of this study was the assessment of hair cortisone and the $\mathrm{R}_{\mathrm{hcc}}$ as potential biomarkers of HPA axis activity along with cortisol. Previous research demonstrated that both cortisone and the $\mathrm{R}_{\mathrm{hcc}}$ are related to various aspects of physical and mental health, which are also associated with cortisol (Quinkler and Stewart, 2003; Romer et al., 2009; Vanaelst et al., 2013; Rippe et al., 2016; Scharlau et al., 2018). Nevertheless, there are virtually no studies that have investigated the effect of social support on cortisone and the $\mathrm{R}_{\mathrm{hcc}}$. The current study demonstrated that the aggregated scales of positive and negative social support were significantly associated with both cortisol and the ratio, whilst only poor children support had an adverse link with cortisone. Such different patterns of associations of social support with cortisol and cortisone remain difficult to interpret owing to the relatively limited number of studies which have used both hormones as biomarkers of stress. Recent research suggested that salivary cortisone may provide a better reflection of systemic cortisol levels because it represents more accurately free serum cortisol levels after adrenal stimulation (Stalder et al., 2013). Furthermore, cortisone seems to be more stable over time (Vanaelst et al., 2013), and it may also be more readily measurable in hair since it has a concentration approximately 3 times higher than cortisol (Staufenbiel et al., 2015). A number of studies reported similar associations of socioeconomic adversity and various stress-related physical conditions (e.g. overweight, diabetes, and cardiometabolic syndrome) with both hair 
cortisol and cortisone (Stalder et al., 2013; Staufenbiel et al., 2015; Noppe et al., 2016; Rippe et al., 2016; Vliegenthart et al., 2016). However, the strength of these relationships was somewhat larger for cortisol as compared with cortisone, a finding which is consistent with the effect of social support observed in this study. This difference may be attributable to a greater influence of biological rather than environmental factors on the levels of cortisone found in human hair. Cortisone is in fact built later in the corticosteroid chain, and is not solely related to cortisol levels (Rippe et al., 2016). For instance, cortisol binds mainly to cortisol binding globulin (CBG) and albumin, whilst only the remaining free fraction (3-10\%) constitutes the bio-active hormone. However, also cortisone binds to CBG, and it is unclear whether only free cortisol or a combination of cortisol and cortisone is built in hair (Raul et al., 2004). Thus, CBG action may influence the strength of the associations of cortisol and cortisone with other environmental factors. Furthermore, it is important to note that age appears to have a curvilinear effect on hair cortisol, where elevated hormone levels are found in young children and older adults (Dettenborn et al., 2012). In contrast, there is no evidence documenting how cortisone and the $\mathrm{R}_{\mathrm{hcc}}$ change across the different stages of the lifespan. Thus, the impact of other biological as well as environmental factors on these biomarkers could differ according to the particular age group examined. Moreover, it also remains unclear whether there is a finite conversion rate which limits the capacity to convert cortisol into cortisone in hair. Notwithstanding these issues, our results clearly suggest that hair cortisone and the $\mathrm{R}_{\mathrm{hcc}}$ may provide useful information about HPA activity, and should therefore be assessed in future research along with cortisol.

In relation to the issue of which dimension of social support has the strongest impact on health, the results appear to suggest that the absence of positive social relationships has a more detrimental effect on the HPA axis than negative social support, particularly in the case of cortisol. Thus, this could indicate that the lack of a warm, reliable, and understanding 
relationship could be more harmful than being exposed to greater criticism and demands from key members of one's own social network. This is in contradiction to previous research indicating a disproportionate impact of negative social support on health and wellbeing (e.g. Rook, 1997; Khondoker et al., 2017). However, it should be noted that the overall quality of social support in this sample was particularly high, which might have limited the ability of this study to detect larger effects of negative social support on hair glucocorticoids. Nevertheless, the benefits of positive social relationships on health have been widely documented (Newsom, 2005). For instance, Okun and Keith (1998) found that positive social exchanges exerted a stronger unique effect on wellbeing and depressive symptoms than negative relationships in older adults, while other researchers reported comparable effects (e.g. Manne and Zautra, 1989). Hence, our results further corroborate such findings.

Lastly, in terms of the effect of different components of social support, children appear to be the most influential source in this sample of older adults. This is consistent with the results of previous studies indicating that positive support from children in particular was associated with fewer depressive symptoms and lower risk of dementia in later life (Okun and Keith, 1998; Khondoker et al., 2017). Such findings could be explained by the fact that the parent-child tie is a unique source of social attachment and solidarity (Umberson, 1992), which has been proposed to affect well-being through supports that meet the needs of both parents and children (Ward, 2008). Furthermore, the parent-child tie plays an increasingly important role as individuals age, since social networks tend to become smaller and focused on emotionally close kin (Ajrouch, et al., 2001).

\subsection{Limitations and suggestions for further research}

This study has a number of limitations which should be carefully considered. First, although the effect of social support was assessed in retrospect over a four-year period, no 
causal conclusions can be drawn because cortisol was measured only once. Second, not all people with detectable hair glucocorticoid concentrations were included in the analysis because some of them did not take part in the self-completion survey in wave 4 . Since the excluded participants were older and had lower socioeconomic position, the sample might not be representative of the general population. Third, another important limitation pertains to the social support scales. In fact, since only a minority of the sample reported low positive or high negative social support, the aggregated scores were not equally representative of all participants with more favourable experiences. Similarly, the source-specific categorical measures of cumulative exposure were based on unbalanced group comparisons. For instance, only about $3 \%$ of the participants reported low positive/high negative partner support twice across the 4-year period of the study, which might have adversely affected the statistical power of the analysis. Furthermore, the 'no source' category and the other nonextreme responses were both assigned a score of zero in the aggregated scales, hence considering them as the same experiences. Nevertheless, including also participants without a particular type of relationship allowed to reduce the amount of missing data. In addition, potential differences between the 'no source' group and the other respondents were addressed in the source-specific analyses. Thus, the use of both categorical and aggregated measures of social support helped to minimise the limitations associated with each approach. Fourth, all social support variables, as well as some of the lifestyle indicators, were measured using selfreport which may be prone to measurement error due to the sensitivity of the information required.

Further research is required to determine the causal effects of social support on the HPA axis using longitudinal assessments of cortisol and cortisone. It would also be interesting to assess the effects of positive and negative experiences of social support on the HPA axis in younger adults to understand whether different sources and dimensions of social 
support may have a different impact on stress throughout the various stages of the lifespan. Additionally, future research should address the relative lack of empirical evidence on the associations of other aspects of social relationships (e.g. social isolation and loneliness) on hair glucocorticoids. Genetic background and early life environment appear to be the main determinants of HPA axis activity along with current life stress (Stephens and Wand, 2012). Thus, given the growing availability of such data in epidemiological surveys, it should be established how the relationships between current social environment, HPA axis, and health are influenced by these characteristics. Lastly, since the current knowledge on hair cortisone and the $\mathrm{R}_{\mathrm{hcc}}$ is still very limited, more methodological research is required to provide a more detailed characterisation of these biomarkers across the various stages of the life course.

\subsection{Conclusions}

To conclude, the current investigation demonstrates that, whilst positive social support within key social relationships is associated with lower hair glucocorticoid concentrations, negative social exchanges may instead increase the risk of HPA axis hyperactivity. Amongst the various sources of social support, children appear to be particularly crucial, whilst associations with other components of social support are weaker. This suggests that it is important to consider multiple sources of support because their aggregated effect may have a larger influence on hormone levels. Given the key role of the HPA axis for several health outcomes, these results therefore provide convincing evidence for the existence of a specific psychobiological pathway underlying the nexus between social support and health. Moreover, they have important implications for health and social care practice. Specifically, they highlight the value of improving the quality of social relationships, rather than merely enhancing social interactions, in order to reduce stress and ameliorate health. 


\section{Contributors}

All authors contributed significantly to the conception, design, analyses or interpretation of data and were involved in revising it critically for intellectual context. The submission of this paper was approved by all researchers.

\section{Funding}

This work was funded by the ESRC-BBSRC Soc-B Centre for Doctoral Training, ES/P000347/1. The English Longitudinal Study of Ageing was developed by a team of researchers based at the University College London, NatCen Social Research, and the Institute for Fiscal Studies and the University of Manchester. The data were collected by NatCen Social Research. The funding is provided by the National Institute of Aging (R01AG017644) and a consortium of UK government departments coordinated by the Economic and Social Research Council. The developers and funders of the English Longitudinal Study of Ageing and the UK Data Archive do not bear any responsibility for the analyses or interpretations presented here. 


\section{References}

Adam, E.K., Hawkley, L.C., Kudielka, B.M., Cacioppo, J. T., 2006. Day-to-day dynamics of experience-cortisol associations in a population-based sample of older adults. PNAS 103(45), 17058-17063.

Adam, E.K., Quinn, M.E., Tavernier, R., McQuillan, M.T., Dahlke, K.A., Gilbert, K. A., 2017. Diurnal cortisol slopes and mental and physical health outcomes: A systematic review and meta-analysis. Psychoneuroendocrinology 83, 25-41.

Ajrouch, K., Antonucci, T., Janevic, M., 2001. Social networks among blacks and whites: The interaction between race and age. J. of Gerontol. Soc. Sci. 56B, S112 -S118.

Berkman, L.F., Krishna, A., 2015. Social network epidemiology. In: Berkman, L.F., Kawachi, I., Glymour, M.M., eds. Social Epidemiology, 2nd Edition. Oxford University Press, New York.

Cohen, S., Underwood, L.G., Gottlieb, B.H., 2000. Social support measurement and intervention: A guide for health and social scientists. Oxford University Press, Oxford.

Croezen, S., Picavet, H.S.J., Haveman-Nies, A., Verschuren, W.M.M., de Groot, L.C., van’t Veer, P., 2012. Do positive or negative experiences of social support relate to current and future health? Results from the Doetinchem Cohort Study. BMC Public Health 12, 65.

Dettenborn, L., Tietze, A., Kirschbaum, C., Stalder, T., 2012. The assessment of cortisol in human hair: Associations with sociodemographic variables and potential confounders. Stress 15(6), 578-588.

DeVries, A.C., Glasper, E.R., Detillion, C.E., 2003. Social modulation of stress responses. Physiol. Behav. 79, 399-407. 
Fiori, K.L., Consedine, N.S., 2013. Positive and negative social exchanges and mental health across the transition to college: Loneliness as a mediator. J. Soc. Personal relatsh. 30(7), 920-941.

Gao, W., Kirschbaum, C., Grass, J., Stalder, T., 2016. LC-MS based analysis of endogenous steroid hormones in human hair. J. Steroid Biochem. Mol. Biol. 162, 92-99.

Girod, J.P., Brotman, D.J., 2004. Does altered glucocorticoid homeostasis increase cardiovascular risk? Cardiovasc. Res. 64, 217-226.

Gottlieb, B.H., Bergen, A.E., 2010. Social support concepts and measures. J. Psychosomatic Res. 69, 511-520.

Hackett, R.A., Kivimaki, M., Kumari, M., Steptoe, A., 2016. Diurnal cortisol patterns, future diabetes, and impaired glucose metabolism in the Whitehall II cohort study. J. Clin. Endocrinol. Metab. 101, 619-625.

Holt-Lunstad, J., Smith, T.B., Layton, J.B., 2010. Social relationships and mortality risk: A metaanalytic review. PLoS Med 7(7), e1000316.

Hostinar, C.E., Gunnar, M.R., 2013. Future Directions in the Study of Social Relationships as Regulators of the HPA Axis Across Development. J. Clin. Child Adolesc. Psychol. 42(4), 564-575.

Jackson, S.E., Kirschbaum, C., Steptoe, A., 2017. Hair Cortisol and Adiposity in a PopulationBased Sample of 2,527 Men and Women Aged 54 to 87 Years. Obes. Biol. Integr. Physiol. 25, 539-544.

Khondoker, M., Rafnsson, S.B., Morris, S., Orrell, M., Steptoe, A., 2017. Positive and Negative Experiences of Social Support and Risk of Dementia in Later Life: An Investigation Using the English Longitudinal Study of Ageing. J. Alzheimer Dis. 58, 99-108. 
Kirschbaum, C., Tietze, A., Skoluda, N., Dettenborn, L., 2009. Hair as a retrospective calendar of cortisol production: Increased cortisol incorporation into hair in the third trimester of pregnancy. Psychoneuroendocrinology 34, 32-37.

Little, R.J.A., Rubin, D.B., 2002. Statistical Analysis with Missing Data, second ed. Willey, Chichester.

Manne, S.L., Zautra, A.J., 1989. Spouse criticism and support: Their association with coping and psychological adjustment among women with rheumatoid arthritis. J. Personal. Soc. Psychol. 56, 608-617.

Marjoribanks, D., Bradley, A., (2017). It takes two: Couple relationships in the UK. Doncaster: Relate. https://www.relate.org.uk/sites/default/files/the_way_we_are_now__it_takes_two.pdf (accessed 6 January 2018).

McEwen, B.S, 1998. Protective and damaging effects of stress mediators. N. Engl. J. Med. 338, 171-79.

McEwen, B.S., 2007. Physiology and neurobiology of stress and adaptation: central role of the brain. Physiol. Rev. 87, 873-904.

McPherson, M., Smith-Lovin, L., 2006. Social Isolation in America: Changes in Core Discussion Networks over Two Decades. Amer. Sociol. Rev. 71, 353-375.

Newsom, J.T., Rook, K.S., Nishishiba, M., Sorkin, D.H., Mahan, T.L., 2005. Understanding the relative importance of positive and negative social exchanges: Examining specific domains and appraisals. J. Gerontol. B. Psychol. Sci. Soc. Sci. 60, P304-P312.

Noppe, G., van den Akker, E.L.T., de Rijke, Y.B., Koper, J.W., Jaddoe, V.W., van Rossum, E.F.C., 2016. Long-term glucocorticoid concentrations as a risk factor for childhood obesity and adverse body-fat distribution. Int. J. Obes. 40, 1503-1509. 
Office for National Statistics, 2016. Measuring national well-being: Life in the UK.

https://www.ons.gov.uk/peoplepopulationandcommunity/wellbeing/articles/measuringnat ionalwellbeing/2016 (accessed 6 January 2018).

Okun, M.A., Keith, V.M., 1998. Effects of Positive and Negative Social Exchanges With Various Sources on Depressive Symptoms in Younger and Older Adults. J. Gerontol. B. Psychol. Sci. Soc. Sci. 60, P304-P312.

Ploubidis, G.B., Benova, L., Grundy, E., Laydon, D., DeStavola, B., 2014. Lifelong Socio Economic Position and biomarkers of later life health: Testing the contribution of competing hypotheses. Soc. Sci. Med. 119, 258-265.

Quinete, N., Bertram, J., Reska, M., Lang, J., Kraus, T., 2015. Highly selective and automated online SPE LC-MS3 method for determination of cortisol and cortisone in human hair as biomarker for stress related diseases. Talanta 134, 310-316.

Quinkler, M., Stewart, P. M., 2003. Hypertension and the cortisol-cortisone shuttle. Clin. Endocrinol. Metab. 88(6), 2384-92.

Raul, J., Cirimele, V., Ludes, B., Kintz, P., 2004. Detection of physiological concentrations of cortisol and cortisone in human hair. Clin. Biochem. 37, 1105-1111.

Rippe, R.C.A., Noppe, G., Windhorst, D.A., Tiemeieret, H., van Rossum, E.F.C., Jaddoe, V.W.V., Verhulst, F.C., Bakermans-Kranenburg, M.J., van IJzendoorn, M.H., van den Akker, E.L.T., 2016. Splitting hair for cortisol? Associations of socio-economic status, ethnicity, hair color, gender and other child characteristics with hair cortisol and cortisone. Psychoneuroendocrinology 66, 56-64.

Romer, B., Lewicka, S., Kopf, D., Lederbogen, F., Hamann, B., Gilles, M., Schilling, C., Onken, V., Frankhauser, P., Deuschle, M., 2009. Cortisol metabolism in depressed patients and healthy controls. Neuroendocrinology 90(3), 301-6. 
Rook, K.S., 1997. Positive and negative social exchanges: Weighing their effects in later life. J Gerontol. B. Psychol. Sci. Soc. Sci. 52, S167-S169.

Scharlau, F., Pietzner, D., Vogel, M., Gaudl, A., Ceglarek, U., Thiery, J., Kratzsch, J., Hiemisch, A., Kiess, W., 2018. Evaluation of hair cortisol and cortisone change during pregnancy and the association with self-reported depression, somatization, and stress symptoms. Stress $21(1), 43-50$.

Stafford, M., Gardner, M., Kumari, M., Kuh, D., Ben-Shlomo, Y., 2013. Social isolation and diurnal cortisol patterns in an ageing cohort. Psychoneuroendocrinology 38, 2737-2745.

Stalder, T., Kirschbaum, C., 2012. Analysis of cortisol in hair - state of the art and future directions. Brain Behav. Immun. 26, 1019-1029.

Stalder, T., Kirschbaum, C., Alexander, N., Bornstein, S.R., Gao, W., Miller, R., Stark, S., Bosch, J. A., Fischer, J.E., 2013. Cortisol in Hair and the Metabolic Syndrome. Endocr. Res. 98(6), 2573-2580.

Stalder, T., Steudte-Schmiedgen, S., Alexander, N., Klucken, T., Vater, A., Wichmann, S., Kirschbaum, C., Miller, R., 2017. Stress-related and basic determinants of hair cortisol in humans: a meta-analysis. Psychoneuroendocrinology 77, 261-274.

Staufenbiel, S.M., Koenders, M., Giltay, E.J., Elzinga, B.M., Manenschijn, L.,Hoencamp, E., van Rossum, E.F.C., Spijker, A.T., 2014. Recent negative life events increase hair cortisol concentrations in patients with bipolar disorder. Stress 17, 451-459.

Staufenbiel, S.M., Penninx, B.W.J.H., De Rijke, Y.B., Van Den Akker, E.L.T., VanRossum, E.F.C., 2015. Determinants of hair cortisol and hair cortisone concentrations in adults. Psychoneuroendocrinology 60, 182-194.

Stephens, M.A.C., Wand, G., 2012. Stress and the HPA axis: Role of Glucocorticoids in Alcohol Dependence. Alcohol Res. 34(4), 468-83. 
Steptoe, A., Owen, N., Kunz-Ebrecht, S.R., Brydon, L., 2004. Loneliness and neuroendocrine, cardiovascular, and inflammatory stress responses in middle-aged men and women. Psychoneuroendocrinology 29(5), 593-611.

Steptoe, A. Tools of psychosocial biology in health care research. In: Bowling A, Ebrahim S, eds. Handbook of Health Research Methods. Maidenhead: Open University Press, 2005:471-93.

Steptoe, A., Breeze, E., Banks, J., Nazroo, J., 2013. Cohort profile: The English longitudinal study of ageing. Int. J. Epidemiol. 42, 1640-1648.

Steptoe, A., Easterlin, E., Kirschbaum, C., 2017. Conscientiousness, hair cortisol concentration, and health behaviour in older men and women. Psychoneuroendocrinology 86, 122-127.

Uchino, B.N., 2006. Social support and health: A review of physiological processes potentially underlying links to disease outcomes. J. Behav. Med. 29, 377-387.

Umberson, D., 1992. Relationships between adult children and their parents: Psychological consequences for both generations. J. Marriage Fam. 54, 664-685.

Van Buuren, S., Groothuis-Oudshoorn, K., 2011. Mice: Multivariate Imputation by Chained Equations in R. J. Stat. Softw. 45(3), 1-67.

Vanaelst, B., Michels, N., De Vriendt, T., Huybrechts, I., Vyncke, K., Sioen, I., Bammann, K., Rivet, N., Raul, J., Molnar, D., De Henauw, S., 2013. Cortisone in hair of elementary school girls and its relationship with childhood stress. Eur. J. Pediatr. 172, 843-846.

Vliegenthart, J., Noppe, G., van Rossum, E.F.C., Koper, J.W., Raat, H., van den Akker, E.L.T., 2016. Socioeconomic status in children is associated with hair cortisol levels as a biological measure of chronic stress. Psychoneuroendocrinology 65, 9-14.

Ward, R.A., 2008. Multiple parent-adult child relations and well-being in middle and later life. J. Gerontol. B. Psychol. Sci. Soc. Sci. 63(4), S239-S247. 
Weber, B., Lewicka, S., Deuschle, M., Colla, M., Vecsei, P., Heuser, I., 2000. Increased Diurnal Plasma Concentrations of Cortisone in Depressed Patients. J. Clin. Endocrinol. Metabol. 85(3), 1133-1136. 
Table 1. Sample characteristics.

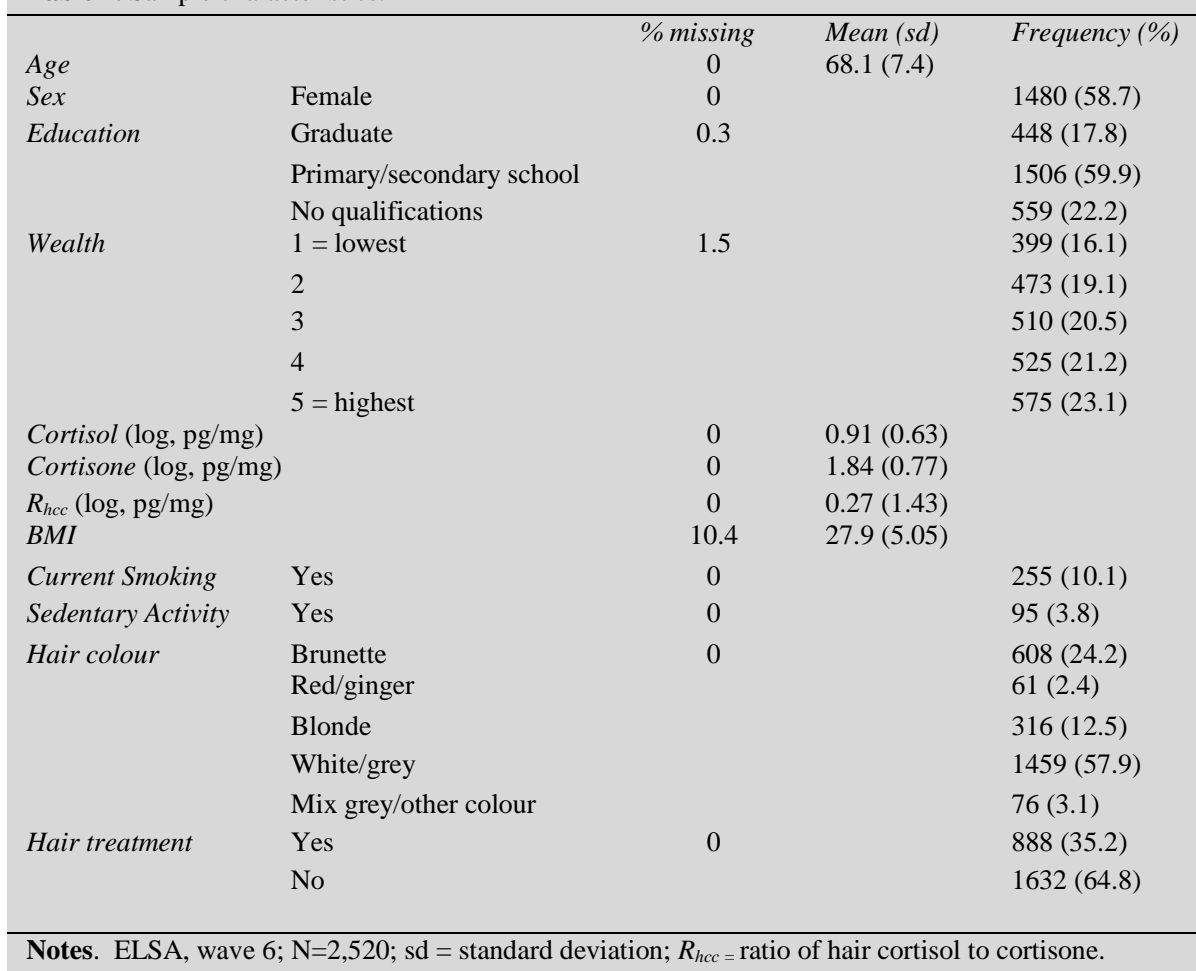


Table 2. Summary statistics of positive and negative social support.

\begin{tabular}{|c|c|c|c|c|c|}
\hline \multirow{2}{*}{\multicolumn{2}{|c|}{$\begin{array}{l}\text { Social support } \\
\text { (wave 6) }\end{array}$}} & \multicolumn{2}{|c|}{ Positive experiences } & \multicolumn{2}{|c|}{ Negative experiences } \\
\hline & & $\%$ missing & Frequency (\%) & $\%$ missing & Frequency (\%) \\
\hline \multirow[t]{4}{*}{ Partner } & High & 5.6 & $1485(62.5)$ & 6.0 & $117(4.9)$ \\
\hline & Medium & & $195(8.2)$ & & $622(26.1)$ \\
\hline & Low & & $63(2.7)$ & & $1007(42.3)$ \\
\hline & No source & & $633(26.6)$ & & $633(26.6)$ \\
\hline \multirow[t]{4}{*}{ Children } & High & 5.7 & $1448(60.9)$ & 6.3 & $70(3.0)$ \\
\hline & Medium & & $478(20.1)$ & & $519(22.0)$ \\
\hline & Low & & $144(6.1)$ & & $1466(62.1)$ \\
\hline & No source & & $306(12.9)$ & & $306(13.0)$ \\
\hline \multirow[t]{4}{*}{ Family } & High & 6.8 & $872(37.1)$ & 15.2 & $78(3.5)$ \\
\hline & Medium & & $779(33.2)$ & & $399(18.1)$ \\
\hline & Low & & $537(22.9)$ & & $1574(71.5)$ \\
\hline & No source & & $160(6.8)$ & & $160(6.8)$ \\
\hline \multirow[t]{4}{*}{ Friends } & High & 5.7 & $1200(50.5)$ & 12.9 & $197(8.5)$ \\
\hline & Medium & & $796(33.5)$ & & $544(23.5)$ \\
\hline & Low & & $248(10.4)$ & & $1445(62.3)$ \\
\hline & No source & & $132(5.6)$ & & $132(5.7)$ \\
\hline \multicolumn{2}{|c|}{ Overall scores } & Mean (sd) & & & \\
\hline \multicolumn{2}{|c|}{ Low positive } & $0.65(0.72)$ & & & \\
\hline \multicolumn{2}{|c|}{ High negative } & $0.36(0.55)$ & & & \\
\hline \multicolumn{2}{|c|}{ Pos. + Neg. } & $1.0(1.0)$ & & & \\
\hline \multirow{2}{*}{\multicolumn{2}{|c|}{$\begin{array}{l}\text { Cumulative Exposure } \\
\text { (waves } 4 \text { \& } 6 \text { ) }\end{array}$}} & \multicolumn{2}{|c|}{ Low Positive } & \multicolumn{2}{|c|}{ High Negative } \\
\hline & & $\%$ missing & Frequency (\%) & $\%$ missing & Frequency (\%) \\
\hline \multirow[t]{4}{*}{ Partner } & 0 times & 12.1 & $1497(67.6)$ & 12.1 & $1402(65.2)$ \\
\hline & 1 time & & $65(2.9)$ & & $143(6.5)$ \\
\hline & 2 times & & $20(2.8)$ & & $37(2.7)$ \\
\hline & No source & & $633(26.6)$ & & $633(26.6)$ \\
\hline \multirow[t]{4}{*}{ Children } & 0 times & 11.9 & $1702(76.7)$ & 12.7 & $1773(81.7)$ \\
\hline & 1 time & & $152(6.8)$ & & $106(4.8)$ \\
\hline & 2 times & & $59(2.7)$ & & $16(0.7)$ \\
\hline & No source & & $306(13.8)$ & & $306(12.8)$ \\
\hline \multirow[t]{4}{*}{ Family } & 0 times & 13.5 & $1333(61.1)$ & 21.7 & $1658(84.0)$ \\
\hline & 1 time & & $415(19.0)$ & & $123(6.2)$ \\
\hline & 2 times & & $273(12.5)$ & & $32(1.6)$ \\
\hline & No source & & $160(7.3)$ & & $160(8.1)$ \\
\hline \multirow[t]{4}{*}{ Friends } & 0 times & 12.1 & $1741(78.6)$ & 19.4 & $1698(83.6)$ \\
\hline & 1 time & & $258(11.6)$ & & $180(8.9)$ \\
\hline & 2 times & & $85(3.8)$ & & $22(1.1)$ \\
\hline & No source & & $132(6.0)$ & & $132(6.5)$ \\
\hline \multicolumn{2}{|c|}{ Overall scores } & $\operatorname{Mean}(s d)$ & & & \\
\hline \multicolumn{2}{|c|}{ Positive } & $1.3(1.20)$ & & & \\
\hline \multicolumn{2}{|c|}{ Negative } & $0.7(1.10)$ & & & \\
\hline \multicolumn{2}{|c|}{ Pos. + Neg. } & $2.0(1.70)$ & & & \\
\hline
\end{tabular}


Table 3. Associations between hair cortisol and positive and negative experiences of social support.

\begin{tabular}{|c|c|c|c|c|c|c|c|c|c|c|}
\hline \multirow{2}{*}{\multicolumn{2}{|c|}{ Outcome: Cortisol (log) }} & \multicolumn{3}{|c|}{ Model 1} & \multicolumn{3}{|c|}{ Model 2} & \multicolumn{3}{|c|}{ Model 3} \\
\hline & & $\mathrm{B}(\mathrm{SE})$ & $\beta$ & $p$-value & $\mathrm{B}(\mathrm{SE})$ & $\beta$ & $p$-value & $\mathrm{B}(\mathrm{SE})$ & $\beta$ & $p$-value \\
\hline \multicolumn{11}{|c|}{ Social Support: cross-sectional } \\
\hline Overall & Low Pos. & $0.043(0.017)$ & 0.049 & 0.014 & $0.041(0.017)$ & 0.048 & 0.018 & & & \\
\hline \multirow[t]{2}{*}{ scores } & High Neg. & $0.054(0.023)$ & 0.047 & 0.019 & $0.044(0.021)$ & 0.039 & 0.051 & & & \\
\hline & Pos. + Neg. & $0.041(0.013)$ & 0.064 & 0.002 & $0.037(0.013)$ & 0.058 & 0.004 & & & \\
\hline \multicolumn{11}{|c|}{ Source-specific: Positive } \\
\hline Partner & High & $0.054(0.078)$ & 0.041 & 0.494 & $0.065(0.079)$ & 0.050 & 0.406 & $0.065(0.080)$ & 0.050 & 0.416 \\
\hline \multirow[t]{2}{*}{ (ref: low) } & Medium & $0.031(0.088)$ & 0.014 & 0.721 & $0.038(0.088)$ & 0.017 & 0.666 & $0.025(0.089)$ & 0.011 & 0.775 \\
\hline & No source & $0.037(0.080)$ & 0.026 & 0.649 & $0.025(0.081)$ & 0.017 & 0.761 & $0.011(0.082)$ & 0.008 & 0.894 \\
\hline Children & High & $-0.117(0.053)$ & -0.092 & 0.026 & $-0.097(0.053)$ & -0.076 & 0.065 & $-0.104(0.053)$ & -0.081 & 0.050 \\
\hline \multirow[t]{2}{*}{ (ref: low) } & Medium & $-0.142(0.057)$ & -0.091 & 0.012 & $-0.127(0.057)$ & -0.081 & 0.026 & $-0.131(0.058)$ & -0.084 & 0.023 \\
\hline & No source & $-0.096(0.061)$ & -0.051 & 0.114 & $-0.066(0.061)$ & -0.035 & 0.280 & $-0.057(0.063)$ & -0.030 & 0.364 \\
\hline Other & High & $-0.046(0.034)$ & -0.035 & 0.170 & $-0.041(0.033)$ & -0.031 & 0.225 & $-0.046(0.035)$ & -0.036 & 0.191 \\
\hline Family & Medium & $-0.064(0.034)$ & -0.049 & 0.059 & $-0.053(0.034)$ & -0.040 & 0.116 & $-0.058(0.034)$ & -0.044 & 0.093 \\
\hline (ref: low) & No source & $-0.075(0.054)$ & -0.030 & 0.167 & $-0.062(0.054)$ & -0.025 & 0.255 & $-0.071(0.055)$ & -0.029 & 0.196 \\
\hline Friends & High & $0.001(0.043)$ & 0.001 & 0.988 & $0.011(0.042)$ & 0.009 & 0.801 & $0.023(0.044)$ & 0.018 & 0.604 \\
\hline \multirow[t]{2}{*}{ (ref: low) } & Medium & $0.027(0.044)$ & 0.020 & 0.543 & $0.041(0.044)$ & 0.031 & 0.348 & $0.052(0.045)$ & 0.039 & 0.243 \\
\hline & No source & $-0.027(0.065)$ & -0.010 & 0.680 & $-0.050(0.066)$ & -0.018 & 0.448 & $-0.047(0.066)$ & -0.017 & 0.470 \\
\hline \multicolumn{11}{|c|}{ Source-specific: Negative } \\
\hline Partner & Low & $-0.079(0.060)$ & -0.062 & 0.187 & $-0.046(0.060)$ & -0.036 & 0.442 & $-0.037(0.063)$ & -0.029 & 0.560 \\
\hline \multirow[t]{2}{*}{ (ref: high) } & Medium & $-0.088(0.062)$ & -0.062 & 0.153 & $-0.061(0.062)$ & -0.043 & 0.323 & $-0.047(0.063)$ & -0.033 & 0.459 \\
\hline & No source & $-0.089(0.062)$ & -0.063 & 0.149 & $-0.082(0.062)$ & -0.058 & 0.184 & $-0.074(0.064)$ & -0.052 & 0.250 \\
\hline Children & Low & $-0.020(0.072)$ & -0.015 & 0.786 & $0.015(0.073)$ & 0.012 & 0.838 & $0.026(0.078)$ & 0.020 & 0.741 \\
\hline \multirow[t]{2}{*}{ (ref: high) } & Medium & $-0.034(0.075)$ & -0.023 & 0.651 & $-0.008(0.075)$ & -0.006 & 0.912 & $-0.004(0.078)$ & -0.002 & 0.962 \\
\hline & No source & $-0.004(0.079)$ & -0.002 & 0.956 & $0.039(0.079)$ & 0.021 & 0.621 & $0.069(0.084)$ & 0.037 & 0.412 \\
\hline Other & Low & $-0.022(0.068)$ & -0.016 & 0.741 & $-0.008(0.068)$ & -0.006 & 0.902 & $-0.010(0.071)$ & -0.007 & 0.894 \\
\hline Family & Medium & $-0.013(0.072)$ & -0.008 & 0.852 & $-0.005(0.073)$ & -0.003 & 0.942 & $-0.004(0.074)$ & -0.002 & 0.960 \\
\hline (ref: high) & No source & $-0.052(0.082)$ & -0.021 & 0.521 & $-0.033(0.082)$ & -0.014 & 0.688 & $-0.036(0.085)$ & -0.015 & 0.671 \\
\hline Friends & Low & $-0.010(0.076)$ & -0.008 & 0.894 & $0.031(0.046)$ & 0.024 & 0.501 & $0.017(0.048)$ & 0.013 & 0.719 \\
\hline \multirow[t]{2}{*}{ (ref high) } & Medium & $0.063(0.078)$ & 0.043 & 0.801 & $0.094(0.050)$ & 0.064 & 0.059 & $0.082(0.051)$ & 0.056 & 0.105 \\
\hline & No source & $-0.001(0.094)$ & -0.000 & 0.995 & $-0.002(0.072)$ & -0.001 & 0.968 & $0.003(0.075)$ & 0.001 & 0.970 \\
\hline \multicolumn{11}{|c|}{ Social support: cumulative exposure } \\
\hline Overall & Low Pos. & $0.030(0.010)$ & 0.058 & 0.004 & $0.028(0.010)$ & 0.055 & 0.006 & & & \\
\hline \multirow[t]{2}{*}{ scores } & High Neg. & $0.027(0.012)$ & 0.046 & 0.021 & $0.022(0.012)$ & 0.038 & 0.060 & & & \\
\hline & Pos. + Neg. & $0.025(0.007)$ & 0.069 & 0.001 & $0.022(0.007)$ & 0.062 & 0.002 & & & \\
\hline
\end{tabular}

Notes. ELSA, waves 4 and $6 ; \mathrm{B}=$ regression coefficients; $\mathrm{SE}=$ standard errors; $\beta=$ standardised coefficients; bold values are statistically significant at $\mathrm{p} \leq 0.05$. 
Table 4. Associations between hair cortisone and positive and negative experiences of social support.

\begin{tabular}{|c|c|c|c|c|c|c|c|c|c|c|}
\hline \multirow{2}{*}{\multicolumn{2}{|c|}{ Outcome: Cortisone (log) }} & \multicolumn{3}{|c|}{ Model 1} & \multicolumn{3}{|c|}{ Model 2} & \multicolumn{3}{|c|}{ Model 3} \\
\hline & & $\mathrm{B}(\mathrm{SE})$ & $\beta$ & $p$-value & $\mathrm{B}(\mathrm{SE})$ & $\beta$ & $p$-value & $\mathrm{B}(\mathrm{SE})$ & $\beta$ & $p$-value \\
\hline \multicolumn{11}{|c|}{ Social Support: cross-sectional } \\
\hline Overall & Low Pos. & $0.023(0.021)$ & 0.022 & 0.261 & $0.016(0.020)$ & 0.015 & 0.421 & & & \\
\hline scores & Pos.+ Neg. & $0.011(0.015)$ & 0.013 & 0.493 & $-0.002(0.015)$ & -0.003 & 0.871 & & & \\
\hline \multicolumn{11}{|c|}{ Source specific: Positive } \\
\hline Partner & High & $0.035(0.093)$ & 0.022 & 0.703 & $0.062(0.091)$ & 0.039 & 0.493 & $0.078(0.092)$ & 0.049 & 0.392 \\
\hline \multirow[t]{2}{*}{ (ref: low) } & Medium & $-0.005(0.104)$ & -0.002 & 0.964 & $0.006(0.101)$ & 0.002 & 0.950 & $-0.009(0.102)$ & -0.003 & 0.929 \\
\hline & No source & $0.142(0.095)$ & 0.081 & 0.136 & $0.125(0.093)$ & 0.071 & 0.180 & $0.126(0.094)$ & 0.071 & 0.182 \\
\hline Children & High & $-0.196(0.062)$ & -0.124 & 0.002 & $-0.159(0.061)$ & -0.100 & 0.009 & $-0.158(0.063)$ & -0.100 & 0.012 \\
\hline \multirow[t]{2}{*}{ (ref: low) } & Medium & $-0.190(0.068)$ & -0.099 & 0.005 & $-0.160(0.066)$ & -0.083 & 0.015 & $-0.159(0.066)$ & -0.083 & 0.016 \\
\hline & No source & $-0.141(0.072)$ & -0.061 & 0.050 & $-0.099(0.070)$ & -0.043 & 0.159 & $-0.112(0.072)$ & -0.048 & 0.120 \\
\hline Other & High & $-0.054(0.040)$ & -0.034 & 0.175 & $-0.045(0.038)$ & -0.027 & 0.245 & $-0.032(0.041)$ & -0.020 & 0.425 \\
\hline Family & Medium & $-0.058(0.040)$ & -0.035 & 0.152 & $-0.034(0.039)$ & -0.021 & 0.384 & $-0.024(0.039)$ & -0.015 & 0.538 \\
\hline (ref: low) & No source & $-0.066(0.064)$ & -0.022 & 0.304 & $-0.049(0.062)$ & -0.016 & 0.428 & $-0.049(0.063)$ & -0.016 & 0.444 \\
\hline Friends & High & $-0.101(0.051)$ & -0.065 & 0.047 & $-0.067(0.049)$ & -0.043 & 0.172 & $-0.060(0.051)$ & -0.039 & 0.237 \\
\hline (ref: low) & Medium & $-0.112(0.052)$ & -0.069 & 0.032 & $-0.085(0.051)$ & -0.052 & 0.092 & $-0.076(0.051)$ & -0.046 & 0.138 \\
\hline \multicolumn{11}{|c|}{ Source-specific: Negative } \\
\hline Partner & Low & $-0.077(0.071)$ & 0.050 & 0.273 & $-0.026(0.069)$ & -0.017 & 0.705 & $0.017(0.072)$ & 0.011 & 0.812 \\
\hline (ref: & Medium & $0.007(0.073)$ & 0.004 & 0.925 & $0.040(0.071)$ & 0.023 & 0.575 & $0.079(0.072)$ & 0.046 & 0.269 \\
\hline high) & No source & $0.071(0.073)$ & 0.040 & 0.333 & $0.072(0.071)$ & 0.041 & 0.314 & $0.112(0.073)$ & 0.064 & 0.127 \\
\hline Children & Low & $-0.261(0.086)$ & -0.164 & 0.002 & $-0.238(0.083)$ & -0.149 & 0.004 & $-0.274(0.089)$ & -0.177 & 0.002 \\
\hline (ref: & Medium & $-0.218(0.089)$ & -0.117 & 0.015 & $-0.216(0.086)$ & -0.116 & 0.013 & $-0.235(0.089)$ & -0.127 & 0.008 \\
\hline high) & No source & $-0.201(0.093)$ & -0.087 & 0.031 & $-0.175(0.090)$ & -0.076 & 0.053 & $-0.211(0.095)$ & -0.092 & 0.027 \\
\hline Other & Low & $0.080(0.080)$ & 0.047 & 0.319 & $0.106(0.079)$ & 0.063 & 0.173 & $0.151(0.081)$ & 0.090 & 0.068 \\
\hline Family & Medium & $0.094(0.085)$ & 0.047 & 0.273 & $0.094(0.083)$ & 0.047 & 0.256 & $0.125(0.084)$ & 0.063 & 0.138 \\
\hline $\begin{array}{l}\text { (ref: } \\
\text { high) }\end{array}$ & No source & $0.054(0.096)$ & 0.018 & 0.578 & $0.083(0.094)$ & 0.028 & 0.377 & $0.115(0.096)$ & 0.039 & 0.233 \\
\hline Friends & Low & $0.030(0.054)$ & 0.018 & 0.581 & $0.070(0.052)$ & 0.044 & 0.185 & $0.080(0.054)$ & 0.050 & 0.142 \\
\hline \multirow[t]{2}{*}{ (ref high) } & Medium & $0.022(0.059)$ & 0.012 & 0.713 & $0.032(0.057)$ & 0.018 & 0.577 & $0.019(0.058)$ & 0.011 & 0.744 \\
\hline & No source & $0.188(0.085)$ & 0.051 & 0.028 & $0.137(0.083)$ & 0.037 & 0.098 & $0.179(0.085)$ & 0.048 & 0.036 \\
\hline \multicolumn{11}{|c|}{ Social Support - cumulative exposure } \\
\hline Overall & Low Pos. & $0.015(0.012)$ & 0.023 & 0.235 & $0.008(0.012)$ & 0.013 & 0.484 & & & \\
\hline scores & High Neg. & $-0.005(0.014)$ & -0.007 & 0.709 & $-0.020(0.014)$ & -0.028 & 0.139 & & & \\
\hline
\end{tabular}


Table 5. Associations between the ratio of hair cortisol to cortisone $\left(R_{h c c}\right)$ and positive and negative experiences of social support.

\begin{tabular}{|c|c|c|c|c|c|c|c|c|c|c|}
\hline \multicolumn{2}{|c|}{ Outcome : $R_{h c c}(\log )$} & \multicolumn{3}{|c|}{ Model 1} & \multicolumn{3}{|c|}{ Model 2} & \multicolumn{3}{|c|}{ Model 3} \\
\hline & & $\mathrm{B}(\mathrm{SE})$ & $\beta$ & $p$-value & $\mathrm{B}(\mathrm{SE})$ & $\beta$ & $p$-value & $\mathrm{B}(\mathrm{SE})$ & $\beta$ & $p$-value \\
\hline \multicolumn{11}{|c|}{ Social Support - cross-sectional } \\
\hline \multirow[t]{3}{*}{ Overall scores } & Low Pos. & $0.074(0.039)$ & 0.038 & 0.059 & $0.078(0.039)$ & 0.039 & 0.048 & & & \\
\hline & High Neg. & $0.130(0.052)$ & 0.050 & 0.012 & $0.136(0.051)$ & 0.053 & 0.008 & & & \\
\hline & Pos.+Neg. & $0.084(0.029)$ & 0.057 & 0.004 & $0.088(0.029)$ & 0.059 & 0.003 & & & \\
\hline \multicolumn{11}{|c|}{ Source-specific: Positive } \\
\hline Partner & High & $0.087(0.177)$ & 0.029 & 0.623 & $0.088(0.178)$ & 0.030 & 0.621 & $0.070(0.180)$ & 0.024 & 0.697 \\
\hline \multirow[t]{2}{*}{ (ref: low) } & Medium & $0.076(0.200)$ & 0.015 & 0.705 & $0.079(0.200)$ & 0.015 & 0.692 & $0.065(0.201)$ & 0.013 & 0.745 \\
\hline & No source & $-0.058(0.182)$ & -0.019 & 0.751 & $-0.068(0.183)$ & -0.021 & 0.709 & $-0.102(0.186)$ & -0.031 & 0.584 \\
\hline Children & High & $-0.074(0.119)$ & -0.025 & 0.534 & $-0.065(0.119)$ & -0.022 & 0.586 & $-0.083(0.124)$ & -0.028 & 0.500 \\
\hline \multirow[t]{2}{*}{ (ref: low) } & Medium & $-0.141(0.129)$ & -0.039 & 0.277 & $-0.134(0.129)$ & -0.038 & 0.298 & $-0.144(0.130)$ & -0.041 & 0.267 \\
\hline & No source & $-0.077(0.138)$ & -0.018 & 0.575 & $-0.051(0.138)$ & -0.012 & 0.712 & $-0.018(0.142)$ & -0.004 & 0.901 \\
\hline Other Family & High & $-0.051(0.076)$ & -0.017 & 0.505 & $-0.048(0.076)$ & -0.016 & 0.528 & $-0.074(0.080)$ & -0.025 & 0.357 \\
\hline \multirow[t]{2}{*}{ (ref: low) } & Medium & $-0.093(0.077)$ & -0.031 & 0.230 & $-0.091(0.077)$ & -0.030 & 0.236 & $-0.111(0.078)$ & -0.037 & 0.154 \\
\hline & No source & $-0.104(0.123)$ & -0.019 & 0.396 & $-0.091(0.123)$ & -0.016 & 0.459 & $-0.115(0.125)$ & -0.020 & 0.359 \\
\hline Friends & High & $0.103(0.097)$ & 0.036 & 0.287 & $-0.067(0.049)$ & -0.043 & 0.172 & $0.113(0.100)$ & 0.040 & 0.261 \\
\hline \multirow[t]{2}{*}{ (ref: low) } & Medium & $0.172(0.100)$ & 0.057 & 0.084 & $-0.085(0.051)$ & -0.052 & 0.092 & $0.194(0.101)$ & 0.064 & 0.055 \\
\hline & No source & $-0.008(0.148)$ & -0.001 & 0.956 & $-0.115(0.075)$ & -0.034 & 0.127 & $-0.008(0.149)$ & -0.001 & 0.955 \\
\hline \multicolumn{11}{|c|}{ Source-specific: Negative } \\
\hline Partner & Low & $-0.105(0.135)$ & -0.036 & 0.439 & $-0.081(0.136)$ & -0.028 & 0.552 & $-0.103(0.142)$ & -0.036 & 0.469 \\
\hline \multirow[t]{2}{*}{ (ref: high) } & Medium & $-0.212(0.139)$ & -0.065 & 0.127 & $-0.183(0.139)$ & -0.057 & 0.189 & $-0.190(0.142)$ & -0.059 & 0.181 \\
\hline & No source & $-0.276(0.139)$ & -0.085 & 0.048 & $-0.263(0.140)$ & -0.081 & 0.061 & $-0.284(0.145)$ & -0.088 & 0.050 \\
\hline Children & Low & $0.215(0.164)$ & 0.073 & 0.191 & $0.272(0.164)$ & 0.092 & 0.098 & $0.332(0.176)$ & 0.113 & 0.059 \\
\hline \multirow[t]{2}{*}{ (ref: high) } & Medium & $0.137(0.171)$ & 0.040 & 0.424 & $0.193(0.170)$ & 0.056 & 0.257 & $0.223(0.176)$ & 0.065 & 0.209 \\
\hline & No source & $0.193(0.178)$ & 0.045 & 0.279 & $0.266(0.178)$ & 0.062 & 0.136 & $0.370(0.189)$ & 0.086 & 0.050 \\
\hline Other Family & Low & $-0.131(0.154)$ & -0.042 & 0.393 & $-0.126(0.154)$ & -0.040 & 0.416 & $-0.173(0.160)$ & -0.055 & 0.281 \\
\hline \multirow[t]{2}{*}{ (ref: high) } & Medium & $-0.131(0.163)$ & -0.036 & 0.422 & $-0.113(0.164)$ & -0.031 & 0.490 & $-0.140(0.166)$ & -0.038 & 0.401 \\
\hline & No source & $-0.173(0.184)$ & -0.032 & 0.393 & $-0.158(0.185)$ & -0.029 & 0.395 & $-0.197(0.190)$ & -0.036 & 0.301 \\
\hline Friends & Low & $0.003(0.103)$ & 0.001 & 0.974 & $0.001(0.103)$ & 0.000 & 0.992 & $-0.042(0.107)$ & -0.014 & 0.695 \\
\hline \multirow[t]{2}{*}{ (ref high) } & Medium & $0.173(0.112)$ & 0.052 & 0.122 & $0.183(0.112)$ & 0.055 & 0.103 & $0.168(0.114)$ & 0.050 & 0.142 \\
\hline & No source & $-0.138(0.162)$ & -0.020 & 0.396 & $-0.144(0.163)$ & -0.021 & 0.377 & $-0.174(0.168)$ & -0.025 & 0.301 \\
\hline \multicolumn{11}{|c|}{ Social Support - cumulative exposure } \\
\hline \multirow[t]{3}{*}{ Overall scores } & Low Pos. & $0.055(0.024)$ & 0.046 & 0.021 & $0.057(0.023)$ & 0.048 & 0.015 & & & \\
\hline & High Neg. & $0.067(0.027)$ & 0.050 & 0.012 & $0.070(0.027)$ & 0.055 & 0.008 & & & \\
\hline & Pos.+Neg. & $0.052(0.016)$ & 0.063 & 0.002 & $0.056(0.016)$ & 0.066 & 0.001 & & & \\
\hline
\end{tabular}

Notes. ELSA, waves 4 and $6 ; \mathrm{B}=$ regression coefficients; $\mathrm{SE}=$ standard errors; $\beta=$ standardised coefficients; bold values are statistically significant at $\mathrm{p} \leq 0.05$. 


\section{Appendix A}

Appendix A. Questionnaire and scale measuring positive and negative experiences of social support.

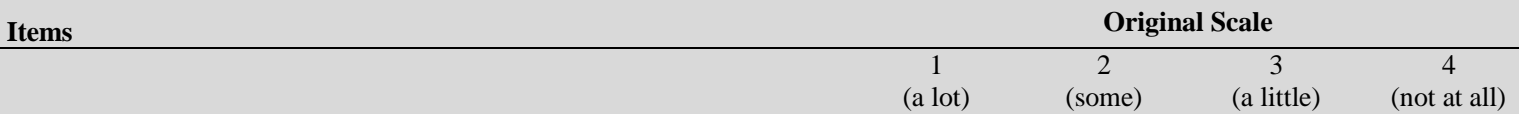

Positive social support $\quad$ (a) How much do they really understand the way you feel about things?

(b) How much can you rely on them if you have a serious problem?

(c) How much can you open up to them if you need if you need to talk about your worries?

Negative social support $\quad$ (a) How much do they criticise you?

(b) How much do they let you down when you are counting on them?

(c) How much do they get on your nerves

(d) How often do they make too many demands on you?

\section{Appendix B}

\begin{tabular}{|c|c|c|c|c|c|c|}
\hline & & & Observ & & Imput & \\
\hline & & $\%$ missing & Mean $(s d)$ & Frequency (\%) & Mean $(s d)$ & $\%$ \\
\hline Age & & 0 & $68.1(7.4)$ & & $68.1(7.4)$ & \\
\hline Sex & Male & 0 & & $1040(41.3)$ & & 41.3 \\
\hline & Female & & & $1480(58.7)$ & & 58.7 \\
\hline Education & Graduate & 0.3 & & $448(17.8)$ & & 17.8 \\
\hline & $\begin{array}{l}\text { Primary/secondary } \\
\text { school }\end{array}$ & & & $1506(59.9)$ & & 59.8 \\
\hline & No qualifications & & & $559(22.2)$ & & 22.2 \\
\hline Wealth & 1 = lowest & 1.5 & & $399(16.1)$ & & 15.9 \\
\hline & 2 & & & $473(19.1)$ & & 19.0 \\
\hline & 3 & & & $510(20.5)$ & & 20.6 \\
\hline & 4 & & & $525(21.2)$ & & 21.2 \\
\hline & $5=$ highest & & & $575(23.1)$ & & 23.3 \\
\hline Cortisol (lo & ,pg/mg) & 0 & $0.91(0.63)$ & & $0.91(0.63)$ & \\
\hline Cortisone & $\mathrm{g}, \mathrm{pg} / \mathrm{mg})$ & 0 & $1.84(0.77)$ & & $1.84(0.77)$ & \\
\hline$R_{h c c}(\log , \mathrm{p}$ & $\mathrm{mg})$ & 0 & $0.27(1.43)$ & & $0.27(1.43)$ & \\
\hline$B M I$ & & 10.4 & $27.9(5.05)$ & & $28.0(5.08)$ & \\
\hline Current & Yes & 0 & & $255(10.1)$ & & 10.1 \\
\hline Smoking & No & & & 2265 (89.9) & & 89.9 \\
\hline Sedentary & Yes & 0 & & $95(3.8)$ & & 3.8 \\
\hline Activity & No & & & $2425(96.2)$ & & 96.2 \\
\hline Hair & Brunette & 0 & & $608(24.2)$ & & 24.2 \\
\hline colour & Red/ginger & & & $61(2.4)$ & & 2.4 \\
\hline & Blonde & & & $316(12.5)$ & & 12.5 \\
\hline & White/grey & & & $1459(57.9)$ & & 57.9 \\
\hline & Mix grey/other colour & & & $76(3.1)$ & & 3.1 \\
\hline Hair & Yes & 0 & & $888(35.2)$ & & 35.2 \\
\hline treatment & No & & & $1632(64.8)$ & & 64.8 \\
\hline
\end{tabular}

Notes. Data source: ELSA, wave 6; $\mathrm{N}=2,520$; only percentages are given for the imputed data as frequencies vary across the 20 imputed datasets. 


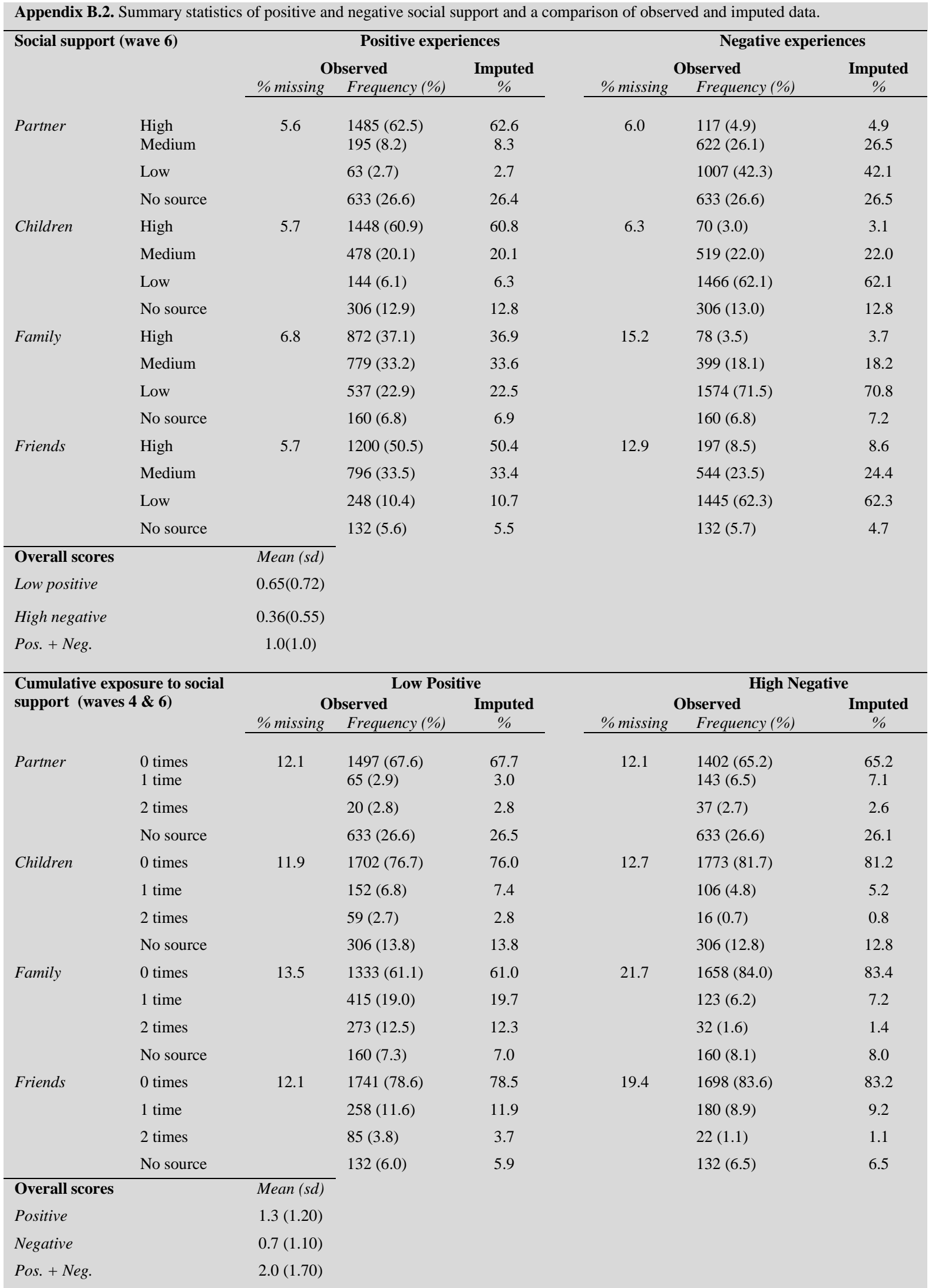

Notes. Data source: ELSA, waves 4 \& 6; $N=2,520$; only percentages are given for the imputed data as frequencies vary across the 20 imputed datasets. Overall scores were only calculated for the imputed datasets. 


\section{Appendix C}

\begin{tabular}{|c|c|c|c|c|c|c|c|c|c|c|}
\hline \multirow{2}{*}{\multicolumn{2}{|c|}{ Outcome: cortisol (log) }} & \multicolumn{3}{|c|}{ Model 1} & \multicolumn{3}{|c|}{ Model 2} & \multicolumn{3}{|c|}{ Model 3} \\
\hline & & $\mathrm{B}(\mathrm{SE})$ & $\beta$ & $p$-value & $\mathrm{B}(\mathrm{SE})$ & $\beta$ & $p$-value & $\mathrm{B}(\mathrm{SE})$ & $\beta$ & $p$-value \\
\hline \multicolumn{11}{|c|}{ Social support - cumulative exposure } \\
\hline \multicolumn{11}{|c|}{ Low positive } \\
\hline Partner & 2 & $0.169(0.141)$ & 0.024 & 0.232 & $0.139(0.141)$ & 0.020 & 0.322 & $0.132(0.142)$ & 0.019 & 0.352 \\
\hline \multirow[t]{2}{*}{ (ref: 0) } & 1 & $-0.078(0.073)$ & -0.021 & 0.287 & $-0.080(0.074)$ & -0.023 & 0.256 & $-0.091(0.074)$ & -0.025 & 0.218 \\
\hline & No source & $-0.014(0.029)$ & -0.010 & 0.630 & $-0.037(0.031)$ & -0.026 & 0.226 & $-0.051(0.031)$ & -0.036 & 0.103 \\
\hline Children & 2 & $0.182(0.076)$ & 0.048 & 0.017 & $0.147(0.075)$ & 0.038 & 0.050 & $0.147(0.076)$ & 0.039 & 0.056 \\
\hline \multirow[t]{2}{*}{ (ref: 0) } & 1 & $0.024(0.048)$ & 0.010 & 0.621 & $0.009(0.048)$ & 0.004 & 0.856 & $0.008(0.049)$ & 0.003 & 0.869 \\
\hline & No source & $0.027(0.038)$ & 0.014 & 0.477 & $0.037(0.038)$ & 0.020 & 0.334 & $0.053(0.039)$ & 0.028 & 0.179 \\
\hline Other Family & 2 & $0.048(0.039)$ & 0.025 & 0.222 & $0.041(0.039)$ & 0.021 & 0.298 & $0.043(0.040)$ & 0.023 & 0.282 \\
\hline \multirow{2}{*}{$($ ref: 0$)$} & 1 & $0.079(0.032)$ & 0.050 & 0.015 & $0.069(0.032)$ & 0.044 & 0.031 & $0.073(0.032)$ & 0.047 & 0.024 \\
\hline & No source & $-0.010(0.050)$ & -0.004 & 0.837 & $-0.006(0.050)$ & -0.002 & 0.904 & $-0.012(0.050)$ & -0.005 & 0.807 \\
\hline Friends & 2 & $-0.003(0.067)$ & -0.001 & 0.969 & $-0.016(0.067)$ & -0.005 & 0.817 & $-0.037(0.068)$ & -0.011 & 0.583 \\
\hline \multirow[t]{2}{*}{ (ref: 0) } & 1 & $-0.007(0.038)$ & -0.004 & 0.853 & $-0.021(0.039)$ & -0.011 & 0.592 & $-0.034(0.039)$ & -0.018 & 0.381 \\
\hline \multirow{2}{*}{\multicolumn{11}{|c|}{ High Negative }} \\
\hline & & & & & & & & & & \\
\hline Partner & 2 & $0.166(0.100)$ & 0.033 & 0.098 & $0.147(0.100)$ & 0.029 & 0.143 & $0.161(0.101)$ & 0.032 & 0.113 \\
\hline \multirow[t]{2}{*}{ (ref: 0$)$} & 1 & $0.017(0.050)$ & 0.007 & 0.732 & $-0.016(0.050)$ & -0.006 & 0.751 & $-0.003(0.051)$ & -0.013 & 0.950 \\
\hline & No source & $-0.006(0.030)$ & -0.004 & 0.846 & $-0.028(0.031)$ & -0.019 & 0.377 & $-0.035(0.032)$ & -0.025 & 0.270 \\
\hline Children & 2 & $0.029(0.141)$ & 0.004 & 0.838 & $0.016(0.141)$ & 0.002 & 0.117 & $0.005(0.143)$ & 0.001 & 0.970 \\
\hline \multirow[t]{2}{*}{ (ref: 0) } & 1 & $-0.014(0.057)$ & -0.005 & 0.811 & $-0.050(0.057)$ & -0.018 & 0.379 & $-0.054(0.059)$ & -0.019 & 0.361 \\
\hline & No source & $0.018(0.038)$ & 0.009 & 0.637 & $0.028(0.038)$ & 0.015 & 0.458 & $0.039(0.039)$ & 0.021 & 0.320 \\
\hline Other Family & 2 & $0.016(0.106)$ & 0.003 & 0.880 & $-0.005(0.107)$ & -0.001 & 0.966 & $-0.000(0.110)$ & -0.000 & 0.998 \\
\hline \multirow[t]{2}{*}{$($ ref: 0$)$} & 1 & $-0.002(0.049)$ & -0.001 & 0.974 & $-0.024(0.049)$ & -0.010 & 0.628 & $-0.015(0.050)$ & -0.006 & 0.771 \\
\hline & No source & $0.004(0.052)$ & 0.001 & 0.942 & $-0.005(0.052)$ & -0.002 & 0.925 & $-0.005(0.052)$ & -0.002 & 0.922 \\
\hline Friends & 2 & $0.046(0.119)$ & 0.008 & 0.700 & $0.018(0.119)$ & 0.003 & 0.878 & $0.025(0.121)$ & 0.004 & 0.835 \\
\hline \multirow{2}{*}{ (ref: 0$)$} & 1 & $-0.049(0.043)$ & -0.023 & 0.259 & $-0.063(0.044)$ & -0.030 & 0.148 & $-0.061(0.044)$ & -0.028 & 0.166 \\
\hline & No source & $-0.014(0.060)$ & -0.005 & 0.815 & $-0.054(0.060)$ & -0.018 & 0.365 & $-0.061(0.060)$ & -0.021 & 0.312 \\
\hline
\end{tabular}

Notes. Source: ELSA, waves 4 and 6; B = regression coefficients; SE = standard errors; $\beta=$ standardised regression coefficients; bold values are statistically significant at $\mathrm{p} \leq 0.05$.

Appendix C.2. Associations between hair cortisone and source-specific measures of cumulative exposure to low positive/high negative social support.

\begin{tabular}{|c|c|c|c|c|c|c|c|c|c|c|}
\hline \multicolumn{2}{|c|}{ Outcome: Cortisone (log) } & \multicolumn{3}{|c|}{ Model 1} & \multicolumn{3}{|c|}{ Model 2} & \multicolumn{3}{|c|}{ Model 3} \\
\hline & & $\mathrm{B}(\mathrm{SE})$ & \multirow[t]{2}{*}{$\beta$} & \multirow[t]{2}{*}{$p$-value } & \multirow[t]{2}{*}{$\mathrm{B}(\mathrm{SE})$} & \multirow[t]{2}{*}{$\beta$} & \multirow[t]{2}{*}{$p$-value } & \multirow[t]{2}{*}{$\mathrm{B}(\mathrm{SE})$} & \multirow[t]{2}{*}{$\beta$} & \multirow[t]{2}{*}{$p$-value } \\
\hline \multicolumn{3}{|c|}{ Social Support - cumulative exposure } & & & & & & & & \\
\hline \multicolumn{11}{|c|}{ Low positive } \\
\hline Partner & 2 & $0.088(0.167)$ & 0.010 & 0.599 & $0.078(0.162)$ & 0.009 & 0.631 & $0.049(0.006)$ & 0.049 & 0.298 \\
\hline \multirow[t]{2}{*}{ (ref: 0 ) } & 1 & $-0.035(0.087)$ & -0.008 & 0.684 & $-0.062(0.085)$ & -0.014 & 0.464 & $-0.086(0.085)$ & -0.019 & 0.313 \\
\hline & No source & $0.112(0.035)$ & 0.064 & 0.001 & $0.070(0.035)$ & 0.040 & 0.046 & $0.058(0.036)$ & 0.033 & 0.109 \\
\hline Children & 2 & $0.207(0.091)$ & 0.044 & 0.022 & $0.187(0.088)$ & 0.041 & 0.049 & $0.157(0.089)$ & 0.033 & 0.086 \\
\hline \multirow{2}{*}{ (ref: 0) } & 1 & $0.163(0.057)$ & 0.055 & 0.004 & $0.111(0.056)$ & 0.038 & 0.046 & $0.102(0.056)$ & 0.035 & 0.070 \\
\hline & No source & $0.061(1.354)$ & 0.004 & 0.176 & $0.064(0.044)$ & 0.028 & 0.142 & $0.049(0.045)$ & 0.021 & 0.277 \\
\hline & 2 & $0.065(0.047)$ & 0.028 & 0.161 & $0.044(0.045)$ & 0.019 & 0.332 & $0.017(0.046)$ & 0.007 & 0.706 \\
\hline \multirow{2}{*}{ (ref: 0) } & 1 & $0.037(0.038)$ & 0.019 & 0.336 & $0.024(0.037)$ & 0.012 & 0.525 & $0.012(0.037)$ & 0.006 & 0.746 \\
\hline & No source & $-0.007(0.059)$ & -0.002 & 0.900 & $-0.009(0.058)$ & -0.003 & 0.880 & $-0.022(0.058)$ & -0.007 & 0.706 \\
\hline Friends & 2 & $0.166(0.080)$ & 0.040 & 0.038 & $0.113(0.077)$ & 0.027 & 0.144 & $0.098(0.078)$ & 0.024 & 0.210 \\
\hline \multirow[t]{2}{*}{ (ref: 0) } & 1 & $0.081(0.046)$ & 0.034 & 0.077 & $0.048(0.044)$ & 0.020 & 0.281 & $0.039(0.045)$ & 0.017 & 0.388 \\
\hline & No source & $0.057(0.065)$ & 0.017 & 0.383 & $-0.037(0.064)$ & -0.011 & 0.561 & $-0.039(0.065)$ & -0.012 & 0.546 \\
\hline \multicolumn{11}{|l|}{ High Negative } \\
\hline Partner & 2 & $0.129(0.119)$ & 0.021 & 0.279 & $0.091(0.115)$ & 0.015 & 0.427 & $0.070(0.116)$ & 0.011 & 0.550 \\
\hline \multirow[t]{2}{*}{ (ref: 0) } & 1 & $-0.019(0.059)$ & -0.006 & 0.747 & $-0.068(0.058)$ & -0.022 & 0.237 & $-0.062(0.058)$ & -0.020 & 0.289 \\
\hline & No source & $0.114(0.035)$ & 0.065 & 0.001 & $0.069(0.036)$ & 0.039 & 0.053 & $0.065(0.037)$ & 0.037 & 0.074 \\
\hline Children & 2 & $0.318(0.167)$ & 0.037 & 0.057 & $0.283(0.162)$ & 0.033 & 0.080 & $0.302(0.164)$ & 0.035 & 0.066 \\
\hline \multirow[t]{2}{*}{ (ref: 0) } & 1 & $0.091(0.067)$ & 0.026 & 0.174 & $0.041(0.066)$ & 0.012 & 0.530 & $0.078(0.068)$ & 0.022 & 0.247 \\
\hline & No source & $0.048(0.045)$ & 0.021 & 0.286 & $0.054(0.043)$ & 0.023 & 0.217 & $0.036(0.045)$ & 0.016 & 0.420 \\
\hline Other Family & 2 & $-0.069(0.125)$ & -0.011 & 0.579 & $-0.151(0.123)$ & -0.023 & 0.220 & $-0.177(0.126)$ & -0.027 & 0.160 \\
\hline \multirow[t]{2}{*}{ (ref: 0$)$} & 1 & $-0.001(0.058)$ & -0.001 & 0.988 & $-0.036(0.056)$ & -0.012 & 0.526 & $-0.032(0.058)$ & -0.011 & 0.582 \\
\hline & No source & $0.033(0.061)$ & 0.010 & 0.591 & $0.035(0.060)$ & 0.011 & 0.555 & $0.033(0.060)$ & 0.010 & 0.586 \\
\hline Friends & 2 & $-0.075(0.142)$ & -0.010 & 0.596 & $-0.164(0.137)$ & -0.022 & 0.231 & $-0.162(0.139)$ & -0.022 & 0.244 \\
\hline \multirow[t]{2}{*}{ (ref: 0) } & 1 & $-0.066(0.051)$ & -0.020 & 0.197 & $-0.092(0.050)$ & -0.034 & 0.067 & $-0.089(0.050)$ & -0.033 & 0.079 \\
\hline & No source & $0.155(0.070)$ & 0.043 & 0.028 & $0.073(0.068)$ & 0.020 & 0.292 & $0.072(0.069)$ & 0.020 & 0.299 \\
\hline
\end{tabular}

Notes. Source: ELSA, waves 4 and 6; B = regression coefficients; $\mathrm{SE}=$ standard errors; $\beta=$ standardised regression coefficients; bold values are statistically significant at $\mathrm{p} \leq 0.05$. 


\begin{tabular}{|c|c|c|c|c|c|c|c|c|c|c|}
\hline \multicolumn{11}{|c|}{$\begin{array}{l}\text { Appendix C.3. Associations between the ratio of hair cortisol to cortisone }\left(R_{h c c}\right) \text { and source-specific measures of cumulative exposure to low positive/hig } \\
\text { negative social support. } \\
\text { Outcome: } R_{h c c}(\log )\end{array}$} \\
\hline & & $\mathrm{B}(\mathrm{SE})$ & $\beta$ & $p$-value & $\mathrm{B}(\mathrm{SE})$ & $\beta$ & $p$-value & $\mathrm{B}(\mathrm{SE})$ & $\beta$ & $p$-value \\
\hline \multicolumn{11}{|c|}{ Social Support - cumulative exposure } \\
\hline Partner & 2 & $0.301(0.319)$ & 0.019 & 0.346 & $0.244(0.319)$ & 0.015 & 0.444 & $0.256(0.322)$ & 0.016 & 0.425 \\
\hline \multirow[t]{2}{*}{ (ref: 0$)$} & 1 & $-0.144(0.167)$ & -0.017 & 0.387 & $-0.131(0.167)$ & -0.016 & 0.435 & $-0.124(0.168)$ & -0.015 & 0.461 \\
\hline & No source & $-0.144(0.066)$ & -0.044 & 0.030 & $-0.155(0.069)$ & -0.048 & 0.025 & $-0.176(0.071)$ & -0.054 & 0.013 \\
\hline \multirow[t]{2}{*}{ (ref: 0$)$} & 1 & $-0.107(0.109)$ & -0.020 & 0.327 & $-0.090(0.110)$ & -0.016 & 0.413 & $-0.083(0.111)$ & -0.015 & 0.457 \\
\hline & No source & $0.005(0.086)$ & 0.001 & 0.955 & $0.023(0.086)$ & 0.005 & 0.788 & $0.075(0.089)$ & 0.017 & 0.399 \\
\hline Other Family & 2 & $0.045(0.089)$ & 0.010 & 0.616 & $0.050(0.088)$ & 0.012 & 0.570 & $0.082(0.091)$ & 0.019 & 0.368 \\
\hline \multirow{2}{*}{ (ref: 0$)$} & 1 & $0.142(0.073)$ & 0.040 & 0.053 & $0.134(0.073)$ & 0.037 & 0.067 & $0.155(0.074)$ & 0.043 & 0.036 \\
\hline & No source & $-0.015(0.113)$ & -0.003 & 0.898 & $-0.003(0.113)$ & -0.001 & 0.975 & $-0.005(0.114)$ & -0.001 & 0.963 \\
\hline Friends & 2 & $-0.172(0.152)$ & -0.022 & 0.260 & $0.113(0.077)$ & 0.027 & 0.144 & $-0.183(0.154)$ & -0.024 & 0.232 \\
\hline \multirow{2}{*}{ (ref: 0) } & 1 & $-0.097(0.087)$ & -0.022 & 0.266 & $0.048(0.044)$ & 0.020 & 0.281 & $-0.117(0.089)$ & -0.027 & 0.187 \\
\hline & No source & $-0.145(0.125)$ & -0.023 & 0.245 & $-0.037(0.064)$ & -0.011 & 0.561 & $-0.173(0.127)$ & -0.028 & 0.174 \\
\hline Partner & 2 & $0.254(0.022)$ & 0.254 & 0.265 & $0.246(0.227)$ & 0.022 & 0.278 & $0.300(0.230)$ & 0.026 & 0.192 \\
\hline \multirow[t]{2}{*}{ (ref: 0) } & 1 & $0.052(0.113)$ & 0.009 & 0.644 & $0.026(0.113)$ & 0.005 & 0.819 & $0.049(0.115)$ & 0.007 & 0.672 \\
\hline & No source & $-0.128(0.067)$ & -0.039 & 0.058 & $-0.133(0.070)$ & -0.041 & 0.059 & $-0.148(0.072)$ & -0.045 & 0.041 \\
\hline Children & 2 & $-0.250(0.319)$ & -0.016 & 0.434 & $-0.244(0.319)$ & -0.015 & 0.444 & $-0.289(0.324)$ & -0.018 & 0.373 \\
\hline \multirow[t]{2}{*}{ (ref: 0) } & 1 & $-0.121(0.129)$ & -0.019 & 0.344 & $-0.156(0.129)$ & -0.024 & 0.229 & $-0.201(0.134)$ & -0.031 & 0.133 \\
\hline & No source & $-0.003(0.085)$ & -0.001 & 0.971 & $0.014(0.085)$ & 0.003 & 0.874 & $0.056(0.088)$ & 0.013 & 0.526 \\
\hline \multirow{3}{*}{$\begin{array}{l}\text { Other Family } \\
\text { (ref: } 0 \text { ) }\end{array}$} & 2 & $0.107(0.239)$ & 0.009 & 0.654 & $0.142(0.242)$ & 0.012 & 0.559 & $0.177(0.248)$ & 0.015 & 0.474 \\
\hline & 1 & $-0.002(0.110)$ & -0.000 & 0.987 & $-0.018(0.111)$ & -0.003 & 0.873 & $-0.001(0.114)$ & -0.000 & 0.996 \\
\hline & No source & $-0.025(0.117)$ & -0.004 & 0.834 & $-0.047(0.117)$ & -0.008 & 0.691 & $-0.045(0.118)$ & -0.008 & 0.702 \\
\hline \multirow{3}{*}{$\begin{array}{l}\text { Friends } \\
\text { (ref: } 0)\end{array}$} & 2 & $0.182(0.270)$ & 0.013 & 0.502 & $0.207(0.270)$ & 0.015 & 0.444 & $0.220(0.274)$ & 0.016 & 0.422 \\
\hline & 1 & $-0.046(0.098)$ & -0.009 & 0.640 & $-0.053(0.099)$ & -0.011 & 0.590 & $-0.051(0.099)$ & -0.010 & 0.607 \\
\hline & No source & $-0.187(0.135)$ & -0.028 & 0.165 & $-0.197(0.136)$ & -0.029 & 0.146 & $-0.212(0.136)$ & -0.031 & 0.121 \\
\hline
\end{tabular}

Notes. Source: ELSA, waves 4 and $6 ; \mathrm{B}=$ regression coefficients; $\mathrm{SE}=$ standard errors; $\beta=$ standardised regression coefficients; bold values are

statistically significant at $\mathrm{p} \leq 0.05$. 


\section{Appendix D}

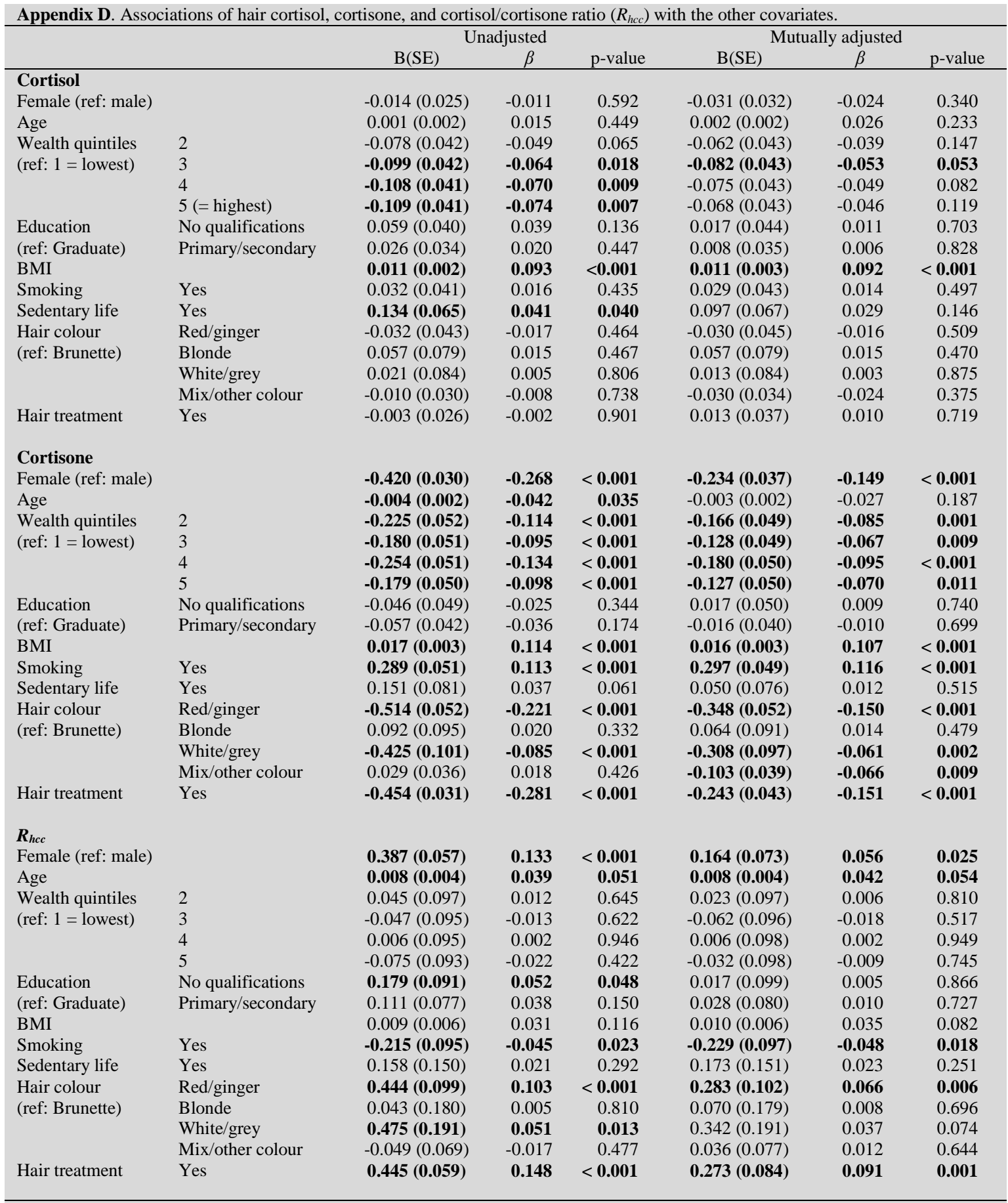

Notes. Source: ELSA, waves 6; $\mathrm{B}=$ regression coefficients; $\mathrm{SE}=$ standard errors; $\beta=$ standardised regression coefficients; bold

values are statistically significant at $\mathrm{p} \leq 0.05$. 


\section{Appendix E}

\begin{tabular}{|c|c|c|c|c|c|c|c|c|c|c|}
\hline \multicolumn{2}{|c|}{ Outcome: Cortisol (log) } & \multicolumn{3}{|c|}{ Model 1} & \multicolumn{3}{|c|}{ Model 2} & \multicolumn{3}{|c|}{ Model 3} \\
\hline & & $\mathrm{B}(\mathrm{SE})$ & $\beta$ & $p$-value & $\mathrm{B}(\mathrm{SE})$ & $\beta$ & $p$-value & $\mathrm{B}(\mathrm{SE})$ & $\beta$ & $p$-value \\
\hline \multicolumn{11}{|c|}{ Social Support - cross-sectional } \\
\hline \multicolumn{11}{|c|}{ Positive } \\
\hline \multirow{3}{*}{$\begin{array}{l}\text { Overall } \\
\text { scores }\end{array}$} & Low Pos. & $0.062(0.024)$ & 0.071 & 0.009 & $0.057(0.024)$ & 0.064 & 0.017 & & & \\
\hline & High Neg. & $0.061(0.032)$ & 0.051 & 0.058 & $0.052(0.032)$ & 0.043 & 0.104 & & & \\
\hline & Pos.+Neg. & $0.054(0.018)$ & 0.081 & 0.002 & $0.049(0.018)$ & 0.072 & 0.006 & & & \\
\hline \multirow{3}{*}{$\begin{array}{l}\text { Partner } \\
\text { (ref: low) }\end{array}$} & High & $0.093(0.121)$ & 0.069 & 0.446 & $0.158(0.122)$ & 0.117 & 0.193 & $0.146(0.123)$ & 0.108 & 0.234 \\
\hline & Medium & $0.130(0.134)$ & 0.054 & 0.332 & $0.175(0.134)$ & 0.073 & 0.191 & $0.165(0.134)$ & 0.068 & 0.221 \\
\hline & No source & $0.044(0.124)$ & 0.029 & 0.726 & $0.078(0.125)$ & 0.053 & 0.531 & $0.050(0.126)$ & 0.034 & 0.688 \\
\hline Children & High & $-0.112(0.078)$ & -0.084 & 0.154 & $-0.097(0.078)$ & -0.072 & 0.216 & $-0.108(0.080)$ & -0.081 & 0.177 \\
\hline \multirow{2}{*}{ (ref: low) } & Medium & $-0.141(0.085)$ & -0.085 & 0.097 & $-0.137(0.084)$ & -0.082 & 0.104 & $-0.141(0.085)$ & -0.085 & 0.095 \\
\hline & No source & $-0.055(0.088)$ & -0.029 & 0.536 & $-0.043(0.088)$ & -0.022 & 0.622 & $-0.023(0.090)$ & -0.012 & 0.793 \\
\hline \multirow{3}{*}{$\begin{array}{l}\text { Other Family } \\
\text { (ref: low) }\end{array}$} & High & $0.017(0.046)$ & 0.011 & 0.709 & $0.008(0.045)$ & 0.005 & 0.855 & $0.019(0.048)$ & 0.012 & 0.677 \\
\hline & Medium & $-0.034(0.040)$ & -0.026 & 0.386 & $-0.035(0.039)$ & -0.026 & 0.368 & $-0.032(0.041)$ & -0.024 & 0.428 \\
\hline & No source & $0.089(0.103)$ & 0.024 & 0.385 & $0.073(0.103)$ & 0.019 & 0.472 & $0.068(0.102)$ & 0.018 & 0.507 \\
\hline \multirow{3}{*}{$\begin{array}{l}\text { Friends } \\
\text { (ref: low) }\end{array}$} & High & $-0.049(0.064)$ & -0.021 & 0.440 & $-0.049(0.063)$ & -0.021 & 0.439 & $-0.053(0.066)$ & -0.023 & 0.423 \\
\hline & Medium & $0.025(0.037)$ & 0.018 & 0.508 & $0.024(0.037)$ & 0.018 & 0.509 & $0.021(0.038)$ & 0.015 & 0.596 \\
\hline & No source & $0.066(0.143)$ & 0.012 & 0.647 & $0.065(0.143)$ & 0.012 & 0.646 & $0.063(0.143)$ & 0.011 & 0.658 \\
\hline \multicolumn{11}{|l|}{ Negative } \\
\hline Partner & Low & $-0.160(0.089)$ & -0.124 & 0.073 & $-0.116(0.090)$ & -0.090 & 0.198 & $-0.114(0.092)$ & -0.088 & 0.215 \\
\hline \multirow[t]{2}{*}{ (ref: high) } & Medium & $-0.183(0.092)$ & -0.125 & 0.048 & $-0.146(0.093)$ & -0.100 & 0.115 & $-0.145(0.093)$ & -0.099 & 0.121 \\
\hline & No source & $-0.210(0.093)$ & -0.142 & 0.024 & $-0.195(0.093)$ & -0.132 & 0.036 & $-0.214(0.095)$ & -0.144 & 0.024 \\
\hline Children & Low & $-0.019(0.116)$ & -0.015 & 0.864 & $0.006(0.116)$ & 0.004 & 0.959 & $0.033(0.119)$ & 0.025 & 0.778 \\
\hline (ref: high) & Medium & $-0.027(0.119)$ & -0.017 & 0.820 & $-0.007(0.120)$ & -0.004 & 0.954 & $0.011(0.120)$ & 0.007 & 0.926 \\
\hline & No source & $0.035(0.123)$ & 0.018 & 0.778 & $0.058(0.123)$ & 0.031 & 0.636 & $0.113(0.125)$ & 0.059 & 0.367 \\
\hline Other Family & Low & $-0.060(0.077)$ & -0.045 & 0.439 & $-0.041(0.078)$ & -0.031 & 0.598 & $-0.045(0.078)$ & -0.033 & 0.562 \\
\hline (ref: high) & Medium & $-0.001(0.081)$ & -0.001 & 0.986 & $0.011(0.081)$ & 0.007 & 0.889 & $0.003(0.082)$ & 0.003 & 0.962 \\
\hline & No source & $0.055(0.125)$ & 0.015 & 0.662 & $0.058(0.124)$ & 0.015 & 0.638 & $0.044(0.124)$ & 0.011 & 0.723 \\
\hline Friends & Low & $-0.000(0.063)$ & -0.000 & 1.000 & $0.024(0.064)$ & 0.017 & 0.713 & $0.020(0.065)$ & 0.014 & 0.757 \\
\hline (ref high) & Medium & $0.048(0.069)$ & 0.032 & 0.485 & $0.066(0.069)$ & 0.044 & 0.339 & $0.052(0.069)$ & 0.035 & 0.450 \\
\hline & No source & $0.099(0.152)$ & 0.019 & 0.518 & $0.096(0.152)$ & 0.018 & 0.531 & $0.078(0.153)$ & 0.014 & 0.610 \\
\hline Social suppor & cumulativ & exposure & & & & & & & & \\
\hline Low positive & & & & & & & & & & \\
\hline Overall & Low Pos. & $0.033(0.014)$ & 0.063 & 0.018 & $0.030(0.014)$ & 0.056 & 0.035 & & & \\
\hline scores & High Neg. & $0.025(0.016)$ & 0.042 & 0.115 & $0.022(0.016)$ & 0.036 & 0.180 & & & \\
\hline & Pos.+Neg. & $0.026(0.009)$ & 0.070 & 0.008 & $0.023(0.009)$ & 0.062 & 0.021 & & & \\
\hline Partner & 2 & $0.167(0.215)$ & 0.020 & 0.436 & $0.069(0.216)$ & 0.008 & 0.749 & $0.067(0.218)$ & 0.008 & 0.756 \\
\hline (ref: 0$)$ & 1 & $-0.158(0.110)$ & -0.038 & 0.151 & $-0.200(0.111)$ & -0.048 & 0.072 & $-0.219(0.111)$ & -0.053 & 0.051 \\
\hline & No source & $-0.054(0.040)$ & -0.037 & 0.178 & $-0.085(0.042)$ & -0.057 & 0.047 & $-0.108(0.044)$ & -0.073 & 0.014 \\
\hline Children & 2 & $0.242(0.117)$ & 0.055 & 0.039 & $0.224(0.117)$ & 0.051 & 0.056 & $0.244(0.119)$ & 0.055 & 0.040 \\
\hline (ref: 0) & 1 & $0.008(0.072)$ & 0.003 & 0.903 & $0.001(0.073)$ & 0.001 & 0.978 & $0.008(0.074)$ & 0.003 & 0.908 \\
\hline & No source & $0.063(0.051)$ & 0.033 & 0.213 & $0.063(0.051)$ & 0.033 & 0.219 & $0.098(0.053)$ & 0.051 & 0.065 \\
\hline Other Family & 2 & $0.051(0.052)$ & 0.027 & 0.322 & $0.039(0.052)$ & 0.020 & 0.450 & $0.046(0.054)$ & 0.024 & 0.394 \\
\hline$($ ref: 0$)$ & 1 & $0.075(0.043)$ & 0.047 & 0.085 & $0.066(0.043)$ & 0.041 & 0.125 & $0.077(0.043)$ & 0.048 & 0.078 \\
\hline & No source & $0.121(0.101)$ & 0.032 & 0.231 & $0.105(0.101)$ & 0.028 & 0.298 & $0.095(0.101)$ & 0.025 & 0.344 \\
\hline Friends & 2 & $-0.020(0.091)$ & -0.006 & 0.826 & $-0.020(0.090)$ & -0.006 & 0.822 & $-0.051(0.092)$ & -0.015 & 0.576 \\
\hline (ref: 0$)$ & 1 & $-0.020(0.091)$ & -0.031 & 0.252 & $-0.065(0.053)$ & -0.032 & 0.219 & $-0.080(0.054)$ & -0.040 & 0.141 \\
\hline & No source & $0.078(0.142)$ & 0.014 & 0.581 & $0.054(0.142)$ & 0.010 & 0.704 & $0.056(0.143)$ & 0.010 & 0.697 \\
\hline High Negative & & & & & & & & & & \\
\hline Partner & 2 & $0.327(0.179)$ & 0.048 & 0.068 & $0.298(0.180)$ & 0.044 & 0.097 & $0.307(0.183)$ & 0.045 & 0.094 \\
\hline (ref: 0$)$ & 1 & $0.004(0.072)$ & 0.001 & 0.955 & $-0.030(0.072)$ & -0.011 & 0.675 & $-0.033(0.074)$ & -0.012 & 0.651 \\
\hline & No source & $-0.056(0.040)$ & -0.038 & 0.164 & $-0.087(0.043)$ & -0.058 & 0.045 & $-0.108(0.045)$ & -0.072 & 0.017 \\
\hline Children & 2 & $0.020(0.289)$ & 0.002 & 0.943 & $0.012(0.289)$ & 0.001 & 0.966 & $-0.103(0.296)$ & -0.009 & 0.727 \\
\hline (ref: 0) & 1 & $-0.019(0.082)$ & -0.006 & 0.813 & $-0.032(0.083)$ & -0.010 & 0.699 & $-0.041(0.085)$ & -0.013 & 0.630 \\
\hline & No source & $0.055(0.051)$ & 0.028 & 0.281 & $0.054(0.051)$ & 0.028 & 0.290 & $0.091(0.053)$ & 0.048 & 0.085 \\
\hline Other Family & 2 & $0.114(0.141)$ & 0.021 & 0.419 & $0.114(0.142)$ & 0.021 & 0.419 & $0.115(0.146)$ & 0.022 & 0.431 \\
\hline (ref: 0$)$ & 1 & $0.064(0.073)$ & 0.023 & 0.383 & $0.044(0.073)$ & 0.016 & 0.542 & $0.058(0.074)$ & 0.021 & 0.428 \\
\hline & No source & $0.101(0.101)$ & 0.027 & 0.311 & $0.087(0.100)$ & 0.023 & 0.381 & $0.082(0.100)$ & 0.022 & 0.412 \\
\hline Friends & 2 & $0.054(0.179)$ & 0.008 & 0.762 & $0.030(0.179)$ & 0.004 & 0.866 & $0.046(0.182)$ & 0.007 & 0.798 \\
\hline (ref: 0 ) & 1 & $-0.046(0.062)$ & -0.019 & 0.457 & $-0.067(0.062)$ & -0.028 & 0.283 & $-0.066(0.062)$ & -0.028 & 0.291 \\
\hline & No source & $0.082(0.142)$ & 0.015 & 0.561 & $0.056(0.142)$ & 0.010 & 0.692 & $0.031(0.142)$ & 0.005 & 0.827 \\
\hline
\end{tabular}

Notes. Source: ELSA, waves 4 and $6 ; \mathrm{B}=$ regression coefficients; $\mathrm{SE}=$ standard errors; $\beta=$ standardised regression coefficients; bold values are statistically significant at $\mathrm{p} \leq 0.05$. 
Appendix E.2. Associations between hair cortisone and positive and negative experiences of social support in complete-case analyses $(\mathrm{N}=1,524)$.

\begin{tabular}{|c|c|c|c|c|c|c|c|c|c|c|}
\hline \multicolumn{2}{|c|}{ Outcome: Cortisone $(\log )$} & \multicolumn{3}{|c|}{ Model 1} & \multicolumn{3}{|c|}{ Model 2} & \multicolumn{3}{|c|}{ Model 3} \\
\hline & & $\mathrm{B}(\mathrm{SE})$ & $\beta$ & $p$-value & $\mathrm{B}(\mathrm{SE})$ & $\beta$ & $p$-value & $\mathrm{B}(\mathrm{SE})$ & $\beta$ & $p$-value \\
\hline \multicolumn{11}{|c|}{ Social Support - cross-sectional } \\
\hline \multicolumn{11}{|c|}{ Positive } \\
\hline \multirow[t]{3}{*}{ Overall scores } & Low Pos. & $0.040(0.039)$ & 0.026 & 0.126 & $0.024(0.026)$ & 0.023 & 0.351 & & & \\
\hline & High Neg. & $-0.006(0.036)$ & -0.004 & 0.852 & $-0.029(0.035)$ & -0.020 & 0.406 & & & \\
\hline & Pos.+Neg. & $0.021(0.020)$ & 0.026 & 0.295 & $0.004(0.019)$ & 0.006 & 0.808 & & & \\
\hline Partner & High & $0.023(0.136)$ & 0.014 & 0.862 & $0.088(0.133)$ & 0.055 & 0.509 & $0.109(0.135)$ & 0.069 & 0.417 \\
\hline \multirow[t]{2}{*}{ (ref: low) } & Medium & $-0.030(0.151)$ & -0.010 & 0.840 & $0.024(0.146)$ & 0.008 & 0.867 & $0.025(0.147)$ & 0.009 & 0.863 \\
\hline & No source & $0.115(0.139)$ & 0.066 & 0.408 & $0.163(0.137)$ & 0.093 & 0.232 & $0.175(0.138)$ & 0.100 & 0.207 \\
\hline Children & High & $-0.166(0.088)$ & -0.106 & 0.058 & $-0.140(0.085)$ & -0.089 & 0.102 & $-0.145(0.088)$ & -0.093 & 0.099 \\
\hline \multirow[t]{2}{*}{ (ref: low) } & Medium & $-0.160(0.095)$ & -0.082 & 0.092 & $-0.137(0.092)$ & -0.070 & 0.137 & $-0.141(0.093)$ & -0.072 & 0.129 \\
\hline & No source & $-0.111(0.099)$ & -0.049 & 0.263 & $-0.098(0.096)$ & -0.044 & 0.307 & $-0.130(0.099)$ & -0.058 & 0.191 \\
\hline Other Family & High & $0.043(0.051)$ & 0.023 & 0.400 & $0.024(0.049)$ & 0.013 & 0.619 & $0.023(0.052)$ & 0.013 & 0.652 \\
\hline \multirow[t]{2}{*}{ (ref: low) } & Medium & $-0.009(0.044)$ & -0.005 & 0.833 & $0.000(0.043)$ & 0.000 & 0.999 & $0.002(0.044)$ & 0.001 & 0.964 \\
\hline & No source & $-0.177(0.115)$ & -0.040 & 0.125 & $-0.166(0.112)$ & -0.037 & 0.138 & $-0.161(0.112)$ & -0.036 & 0.150 \\
\hline Friends & High & $0.048(0.071)$ & 0.018 & 0.498 & $0.019(0.069)$ & 0.007 & 0.781 & $0.005(0.072)$ & 0.001 & 0.943 \\
\hline \multirow{2}{*}{ (ref: low) } & Medium & $-0.021(0.042)$ & -0.013 & 0.607 & $-0.026(0.040)$ & -0.016 & 0.519 & $-0.024(0.042)$ & -0.015 & 0.567 \\
\hline & No source & $0.102(0.161)$ & 0.016 & 0.525 & $0.036(0.156)$ & 0.005 & 0.815 & $0.042(0.157)$ & 0.006 & 0.785 \\
\hline \multicolumn{11}{|l|}{ Negative } \\
\hline & Low & $-0.064(0.100)$ & -0.042 & 0.526 & $-0.034(0.099)$ & -0.022 & 0.731 & $-0.004(0.101)$ & -0.003 & 0.961 \\
\hline \multirow[t]{2}{*}{ (ref: high) } & Medium & $0.053(0.103)$ & 0.030 & 0.609 & $0.057(0.101)$ & 0.033 & 0.572 & $0.073(0.102)$ & 0.042 & 0.475 \\
\hline & No source & $0.078(0.104)$ & 0.045 & 0.451 & $0.085(0.101)$ & 0.048 & 0.403 & $0.108(0.103)$ & 0.062 & 0.296 \\
\hline Children & Low & $-0.162(0.130)$ & -0.103 & 0.213 & $-0.151(0.127)$ & -0.096 & 0.234 & $-0.147(0.130)$ & -0.094 & 0.256 \\
\hline (ref: high) & Medium & $-0.075(0.134)$ & -0.040 & 0.576 & $-0.083(0.130)$ & -0.045 & 0.524 & $-0.086(0.132)$ & -0.046 & 0.511 \\
\hline & No source & $-0.092(0.138)$ & -0.041 & 0.505 & $-0.097(0.134)$ & -0.043 & 0.467 & $-0.119(0.137)$ & -0.053 & 0.385 \\
\hline Other Family & Low & $-0.013(0.087)$ & -0.008 & 0.880 & $0.033(0.085)$ & 0.021 & 0.692 & $0.039(0.086)$ & 0.024 & 0.650 \\
\hline (ref: high) & Medium & $0.058(0.092)$ & 0.034 & 0.525 & $0.079(0.089)$ & 0.046 & 0.372 & $0.087(0.089)$ & 0.051 & 0.329 \\
\hline & No source & $-0.179(0.140)$ & -0.040 & 0.201 & $-0.129(0.136)$ & -0.029 & 0.343 & $-0.105(0.136)$ & -0.024 & 0.437 \\
\hline Friends & Low & $-0.009(0.071)$ & -0.006 & 0.890 & $0.025(0.070)$ & 0.015 & 0.719 & $0.060(0.071)$ & 0.037 & 0.400 \\
\hline (ref high) & Medium & $-0.015(0.078)$ & -0.008 & 0.847 & $-0.004(0.075)$ & -0.002 & 0.951 & $-0.004(0.076)$ & -0.002 & 0.954 \\
\hline & No source & $0.094(0.172)$ & 0.015 & 0.583 & $0.058(0.167)$ & 0.009 & 0.728 & $0.080(0.168)$ & 0.012 & 0.632 \\
\hline Social support & umulative & osure & & & & & & & & \\
\hline Low positive & & & & & & & & & & \\
\hline Overall scores & Low Pos. & $0.019(0.015)$ & 0.031 & 0.226 & $0.008(0.015)$ & 0.013 & 0.600 & & & \\
\hline & High Neg. & $-0.002(0.018)$ & -0.003 & 0.906 & $-0.015(0.018)$ & -0.021 & 0.401 & & & \\
\hline & Pos.+Neg. & $0.008(0.011)$ & 0.020 & 0.433 & $-0.001(0.010)$ & -0.003 & 0.892 & & & \\
\hline Partner & 2 & $-0.024(0.242)$ & -0.002 & 0.920 & $-0.123(0.237)$ & -0.013 & 0.602 & $-0.153(0.240)$ & -0.016 & 0.522 \\
\hline (ref: 0) & 1 & $-0.076(0.124)$ & -0.015 & 0.539 & $-0.114(0.125)$ & -0.023 & 0.345 & $-0.131(0.122)$ & -0.027 & 0.285 \\
\hline & No source & $0.095(0.045)$ & 0.054 & 0.036 & $0.079(0.047)$ & 0.045 & 0.090 & $0.076(0.049)$ & 0.043 & 0.119 \\
\hline Children & 2 & $0.185(0.132)$ & 0.036 & 0.161 & $0.150(0.128)$ & 0.029 & 0.244 & $0.138(0.131)$ & 0.026 & 0.290 \\
\hline (ref: 0) & 1 & $0.083(0.081)$ & 0.026 & 0.310 & $0.040(0.080)$ & 0.012 & 0.613 & $0.040(0.081)$ & 0.012 & 0.619 \\
\hline & No source & $0.054(0.057)$ & 0.024 & 0.341 & $0.039(0.056)$ & 0.017 & 0.483 & $0.011(0.058)$ & 0.005 & 0.846 \\
\hline Other Family & 2 & $0.079(0.058)$ & 0.035 & 0.177 & $0.054(0.057)$ & 0.024 & 0.338 & $0.056(0.059)$ & 0.025 & 0.341 \\
\hline (ref: 0) & 1 & $0.018(0.048)$ & 0.010 & 0.701 & $-0.004(0.047)$ & -0.002 & 0.920 & $-0.001(0.048)$ & -0.001 & 0.980 \\
\hline & No source & $-0.169(0.114)$ & -0.038 & 0.137 & $-0.165(0.110)$ & 0.037 & 0.134 & $-0.165(0.110)$ & -0.037 & 0.136 \\
\hline Friends & 2 & $0.054(0.102)$ & 0.013 & 0.594 & $0.017(0.099)$ & 0.004 & 0.860 & $-0.003(0.101)$ & -0.000 & 0.975 \\
\hline (ref: 0) & 1 & $-0.009(0.060)$ & -0.004 & 0.877 & $-0.025(0.058)$ & -0.010 & 0.668 & $-0.033(0.059)$ & -0.014 & 0.571 \\
\hline & No source & $0.108(0.160)$ & 0.017 & 0.498 & $0.043(0.155)$ & 0.006 & 0.780 & $0.060(0.158)$ & 0.009 & 0.703 \\
\hline High Negative & & & & & & & & & & \\
\hline Partner & 2 & $0.230(0.202)$ & 0.029 & 0.254 & $0.129(0.197)$ & 0.016 & 0.512 & $0.106(0.200)$ & 0.013 & 0.594 \\
\hline (ref: 0) & 1 & $-0.020(0.081)$ & -0.006 & 0.797 & $-0.044(0.079)$ & -0.014 & 0.579 & $-0.043(0.081)$ & -0.013 & 0.595 \\
\hline & No source & $0.089(0.046)$ & 0.051 & 0.051 & $0.072(0.047)$ & 0.041 & 0.129 & $0.066(0.049)$ & 0.037 & 0.183 \\
\hline Children & 2 & $0.298(0.325)$ & 0.023 & 0.360 & $0.232(0.317)$ & 0.018 & 0.463 & $0.308(0.325)$ & 0.024 & 0.342 \\
\hline (ref: 0) & 1 & $0.060(0.093)$ & 0.016 & 0.520 & $0.023(0.091)$ & 0.006 & 0.799 & $0.038(0.093)$ & 0.010 & 0.679 \\
\hline & No source & $0.048(0.057)$ & 0.021 & 0.402 & $0.034(0.056)$ & 0.015 & 0.541 & $0.018(0.058)$ & 0.008 & 0.757 \\
\hline Other Family & 2 & $-0.212(0.159)$ & -0.034 & 0.183 & $-0.282(0.155)$ & -0.045 & 0.069 & $-0.308(0.160)$ & -0.049 & 0.054 \\
\hline (ref: 0$)$ & 1 & $0.096(0.082)$ & 0.029 & 0.243 & $0.086(0.080)$ & 0.026 & 0.283 & $-0.167(0.110)$ & -0.037 & 0.129 \\
\hline & No source & $-0.181(0.113)$ & -0.041 & 0.108 & $-0.170(0.109)$ & -0.038 & 0.119 & $0.090(0.081)$ & 0.027 & 0.268 \\
\hline Friends & 2 & $0.126(0.202)$ & 0.015 & 0.532 & $0.027(0.196)$ & 0.003 & 0.890 & $0.018(0.199)$ & 0.002 & 0.925 \\
\hline (ref: 0) & 1 & $-0.041(0.070)$ & -0.015 & 0.552 & $-0.062(0.068)$ & -0.022 & 0.364 & $-0.067(0.068)$ & -0.024 & 0.325 \\
\hline & No source & $0.103(0.160)$ & 0.016 & 0.519 & $0.039(0.155)$ & 0.006 & 0.802 & $0.027(0.156)$ & 0.004 & 0.862 \\
\hline
\end{tabular}


Appendix E.3. Associations between $R_{h c c}$ and positive and negative experiences of social support in complete-case analyses $(\mathrm{N}=1,524)$.

\begin{tabular}{|c|c|c|c|c|c|c|c|c|c|c|}
\hline \multicolumn{2}{|c|}{ Outcome: $R_{h c c}(\log )$} & \multicolumn{3}{|c|}{ Model 1} & \multicolumn{3}{|c|}{ Model 2} & \multicolumn{3}{|c|}{ Model 3} \\
\hline & & $\mathrm{B}(\mathrm{SE})$ & $\beta$ & $p$-value & $\mathrm{B}(\mathrm{SE})$ & $\beta$ & $p$-value & $\mathrm{B}(\mathrm{SE})$ & $\beta$ & $p$-value \\
\hline \multicolumn{11}{|c|}{ Social Support - cross-sectional } \\
\hline \multicolumn{11}{|c|}{ Positive } \\
\hline \multirow[t]{3}{*}{ Overall scores } & Low Pos. & $0.101(0.053)$ & 0.050 & 0.057 & $0.105(0.053)$ & 0.052 & 0.049 & & & \\
\hline & High Neg. & $0.147(0.072)$ & 0.054 & 0.040 & $0.151(0.072)$ & 0.055 & 0.036 & & & \\
\hline & Pos.+Neg. & $0.103(0.040)$ & 0.068 & 0.010 & $0.107(0.040)$ & 0.070 & 0.008 & & & \\
\hline \multirow{2}{*}{$\begin{array}{l}\text { Partner } \\
\text { (ref: low) }\end{array}$} & High & $0.190(0.272)$ & 0.062 & 0.486 & $0.277(0.274)$ & 0.090 & 0.311 & $0.228(0.276)$ & 0.074 & 0.409 \\
\hline & No source & $-0.015(0.279)$ & -0.004 & 0.272 & $0.016(0.281)$ & 0.004 & 0.953 & $-0.058(0.284)$ & -0.017 & 0.836 \\
\hline \multirow{3}{*}{$\begin{array}{l}\text { Children } \\
\text { (ref: low) }\end{array}$} & High & $-0.088(0.176)$ & -0.029 & 0.614 & $-0.082(0.176)$ & -0.027 & 0.642 & $-0.104(0.181)$ & -0.034 & 0.565 \\
\hline & Medium & $-0.163(0.190)$ & -0.043 & 0.392 & $-0.178(0.190)$ & -0.047 & 0.938 & $-0.185(0.190)$ & -0.049 & 0.332 \\
\hline & No source & $-0.014(0.199)$ & -0.003 & 0.941 & $-0.001(0.198)$ & -0.000 & 0.993 & $0.075(0.204)$ & 0.017 & 0.711 \\
\hline \multirow{3}{*}{$\begin{array}{l}\text { Other Family } \\
\text { (ref: low) }\end{array}$} & High & $-0.004(0.102)$ & -0.001 & 0.964 & $-0.006(0.102)$ & -0.001 & 0.951 & $0.022(0.107)$ & 0.006 & 0.835 \\
\hline & Medium & $-0.068(0.089)$ & -0.022 & 0.441 & $-0.081(0.089)$ & -0.026 & 0.362 & $-0.075(0.092)$ & -0.024 & 0.413 \\
\hline & No source & $0.382(0.231)$ & 0.045 & 0.098 & $0.335(0.230)$ & 0.039 & 0.146 & $0.317(0.230)$ & 0.037 & 0.168 \\
\hline \multirow{2}{*}{$\begin{array}{l}\text { Friends } \\
\text { (ref: low) }\end{array}$} & High & $-0.171(0.143)$ & -0.032 & 0.232 & $0.019(0.069)$ & 0.007 & 0.781 & $-0.129(0.149)$ & -0.024 & 0.386 \\
\hline & No source & $0.099(0.008)$ & 0.321 & 0.758 & $0.036(0.156)$ & 0.005 & 0.815 & $0.102(0.322)$ & 0.008 & 0.750 \\
\hline \multicolumn{11}{|l|}{ Negative } \\
\hline \multirow{3}{*}{$\begin{array}{l}\text { Partner } \\
\text { (ref: high) }\end{array}$} & Low & $-0.307(0.201)$ & -0.105 & 0.127 & $-0.236(0.203)$ & -0.080 & 0.244 & $-0.261(0.207)$ & -0.089 & 0.207 \\
\hline & Medium & $-0.475(0.207)$ & -0.142 & 0.022 & $-0.395(0.208)$ & -0.119 & 0.058 & $-0.408(0.210)$ & -0.122 & 0.207 \\
\hline & No source & $-0.564(0.208)$ & -0.167 & 0.006 & $-0.537(0.208)$ & -0.159 & 0.010 & $-0.605(0.213)$ & -0.179 & 0.004 \\
\hline Children & Low & $0.117(0.261)$ & 0.038 & 0.652 & $0.165(0.261)$ & 0.054 & 0.527 & $0.226(0.266)$ & 0.074 & 0.395 \\
\hline (ref: high) & Medium & $0.012(0.269)$ & 0.003 & 0.963 & $0.067(0.269)$ & 0.018 & 0.802 & $0.112(0.270)$ & 0.031 & 0.677 \\
\hline & No source & $0.172(0.277)$ & 0.039 & 0.534 & $0.231(0.277)$ & 0.053 & 0.403 & $0.381(0.282)$ & 0.088 & 0.176 \\
\hline Other Family & Low & $-0.125(0.175)$ & -0.041 & 0.474 & $-0.128(0.175)$ & -0.042 & 0.463 & $-0.144(0.177)$ & -0.047 & 0.414 \\
\hline (ref: high) & Medium & $-0.060(0.184)$ & -0.018 & 0.744 & $-0.051(0.184)$ & -0.015 & 0.778 & $-0.077(0.184)$ & -0.023 & 0.675 \\
\hline & No source & $0.304(0.280)$ & 0.035 & 0.279 & $0.262(0.279)$ & 0.030 & 0.348 & $0.206(0.279)$ & 0.024 & 0.460 \\
\hline Friends & Low & $0.010(0.143)$ & 0.003 & 0.943 & $0.029(0.143)$ & 0.009 & 0.839 & $-0.013(0.146)$ & -0.004 & 0.925 \\
\hline (ref high) & Medium & $0.128(0.155)$ & 0.037 & 0.410 & $0.159(0.155)$ & 0.046 & 0.306 & $0.127(0.156)$ & 0.037 & 0.416 \\
\hline & No source & $0.133(0.344)$ & 0.011 & 0.699 & $0.162(0.344)$ & 0.013 & 0.636 & $0.099(0.344)$ & 0.008 & 0.772 \\
\hline Social support & cumulative & xposure & & & & & & & & \\
\hline Low positive & & & & & & & & & & \\
\hline Overall scores & Low Pos. & $0.056(0.031)$ & 0.047 & 0.073 & $0.059(0.031)$ & 0.050 & 0.060 & & & \\
\hline Partner & 2 & $0.410(0.484)$ & 0.022 & 0.397 & $0.283(0.486)$ & 0.015 & 0.560 & $0.309(0.490)$ & 0.016 & 0.528 \\
\hline (ref: 0) & 1 & $-0.290(0.248)$ & -0.030 & 0.243 & $-0.346(0.249)$ & -0.036 & 0.165 & $-0.374(0.251)$ & -0.039 & 0.136 \\
\hline & No source & $-0.222(0.090)$ & -0.066 & 0.014 & $-0.276(0.096)$ & -0.082 & 0.004 & $-0.327(0.100)$ & -0.097 & 0.001 \\
\hline Children & 2 & $0.370(0.264)$ & 0.037 & 0.162 & $0.366(0.264)$ & 0.036 & 0.166 & $0.424(0.268)$ & 0.042 & 0.114 \\
\hline (ref: 0) & 1 & $-0.063(0.163)$ & -0.010 & 0.698 & $-0.036(0.165)$ & -0.005 & 0.825 & $-0.021(0.167)$ & -0.003 & 0.899 \\
\hline & No source & $0.090(0.115)$ & 0.021 & 0.430 & $0.105(0.115)$ & 0.024 & 0.363 & $0.214(0.120)$ & 0.049 & 0.074 \\
\hline Other Family & 2 & $0.051(0.118)$ & 0.011 & 0.664 & $0.034(0.117)$ & 0.007 & 0.767 & $0.056(0.122)$ & 0.012 & 0.646 \\
\hline$($ ref: 0$)$ & 1 & $0.148(0.100)$ & 0.039 & 0.139 & $0.157(0.097)$ & 0.043 & 0.108 & $0.177(0.101)$ & 0.047 & 0.081 \\
\hline & No source & $0.447(0.227)$ & 0.052 & 0.049 & $0.405(0.227)$ & 0.047 & 0.074 & $0.383(0.227)$ & 0.045 & 0.091 \\
\hline Friends & 2 & $-0.097(0.205)$ & -0.012 & 0.636 & $-0.059(0.204)$ & -0.007 & 0.770 & $-0.106(0.207)$ & -0.013 & 0.607 \\
\hline (ref: 0) & 1 & $-0.115(0.122)$ & -0.025 & 0.346 & $-0.105(0.122)$ & -0.022 & 0.390 & $-0.135(0.124)$ & -0.029 & 0.277 \\
\hline & No source & $0.071(0.320)$ & 0.005 & 0.824 & $0.080(0.320)$ & 0.006 & 0.801 & $0.068(0.323)$ & 0.005 & 0.832 \\
\hline High Negative & & & & & & & & & & \\
\hline Partner & 2 & $0.523(0.404)$ & 0.034 & 0.194 & $0.559(0.404)$ & 0.036 & 0.167 & $0.600(0.411)$ & 0.039 & 0.144 \\
\hline (ref: 0) & 1 & $0.030(0.162)$ & 0.005 & 0.850 & $-0.025(0.163)$ & -0.004 & 0.877 & $-0.033(0.166)$ & -0.005 & 0.841 \\
\hline & No source & $-0.222(0.092)$ & -0.065 & 0.015 & $-0.273(0.097)$ & -0.080 & 0.005 & $-0.316(0.102)$ & -0.093 & 0.001 \\
\hline Children & 2 & $-0.251(0.650)$ & -0.010 & 0.700 & $-0.204(0.651)$ & -0.008 & 0.753 & $-0.547(0.666)$ & -0.022 & 0.411 \\
\hline (ref: 0) & 1 & $-0.105(0.186)$ & -0.015 & 0.571 & $-0.097(0.187)$ & -0.013 & 0.603 & $-0.133(0.191)$ & -0.019 & 0.486 \\
\hline & No source & $0.077(0.114)$ & 0.018 & 0.499 & $0.089(0.115)$ & 0.020 & 0.436 & $0.193(0.119)$ & 0.044 & 0.107 \\
\hline Other Family & 2 & $0.476(0.319)$ & 0.039 & 0.135 & 0.547 (0.319) & 0.045 & 0.087 & $0.573(0.327)$ & 0.047 & 0.080 \\
\hline (ref: 0$)$ & 1 & $0.050(0.165)$ & 0.008 & 0.760 & $0.016(0.165)$ & 0.002 & 0.921 & $0.044(0.166)$ & 0.007 & 0.788 \\
\hline & No source & $0.414(0.226)$ & 0.048 & 0.066 & $0.371(0.225)$ & 0.043 & 0.099 & $0.355(0.225)$ & 0.041 & 0.115 \\
\hline Friends & 2 & $-0.001(0.404)$ & -0.000 & 0.996 & $0.042(0.404)$ & 0.002 & 0.916 & $0.088(0.409)$ & 0.005 & 0.828 \\
\hline (ref: 0) & 1 & $-0.065(0.140)$ & -0.012 & 0.639 & $-0.093(0.140)$ & -0.017 & 0.508 & $-0.085(0.141)$ & -0.016 & 0.542 \\
\hline & No source & $0.086(0.319)$ & 0.007 & 0.788 & $0.090(0.320)$ & 0.007 & 0.778 & $0.044(0.320)$ & 0.003 & 0.890 \\
\hline
\end{tabular}

Notes. Source: ELSA, waves 4 and $6 ; \mathrm{B}=$ regression coefficients; $\mathrm{SE}=$ standard errors; $\beta=$ standardised regression coefficients; bold values are statistically significant at $\mathrm{p} \leq 0.05$. 


\section{Conflicts of interest}

None of the authors have any conflicts of interest to declare related to the findings of this study. 